\title{
Function and Dysfunction of Microglia during Brain Development: Consequences for Synapses and Neural Circuits
}

\author{
Rosa C. Paolicelli1,2*t and Maria T. Ferretti1,2* \\ ${ }^{1}$ IREM, Institute for Regenerative Medicine, University of Zurich, Zürich, Switzerland, ${ }^{2}$ ZNZ Neuroscience Center Zurich, \\ Zürich, Switzerland
}

Many diverse factors, ranging from stress to infections, can perturb brain homeostasis and alter the physiological activity of microglia, the immune cells of the central nervous system. Microglia play critical roles in the process of synaptic maturation and brain wiring during development. Any perturbation affecting microglial physiological function during critical developmental periods could result in defective maturation of synaptic circuits. In this review, we critically appraise the recent literature on the alterations of microglial activity induced by environmental and genetic factors occurring at pre- and early post-natal stages. Furthermore, we discuss the long-lasting consequences of early-life microglial perturbation on synaptic function and on vulnerability to neurodevelopmental and psychiatric disorders.

\section{OPEN ACCESS}

Edited by:

Owen Murray Rennert,

National Institute of Child Health and Human Development (NIH), USA

Reviewed by: Jason D. Shepherd

University of Utah, USA Irmgard Dorothea Dietzel-Meyer, Ruhr University Bochum, Germany

${ }^{*}$ Correspondence:

Rosa C. Paolicell rosachiara.paolicelli@irem.uzh.ch Maria T. Ferretti mariateresa.ferretti@irem.uzh.ch

${ }^{\dagger}$ These authors have contributed equally to this work.

Received: 29 January 2017 Accepted: 27 April 2017 Published: 10 May 2017

Citation:

Paolicelli RC and Ferretti MT (2017) Function and Dysfunction of Microglia during Brain Development: Consequences for Synapses and Neural Circuits.

Front. Synaptic Neurosci. 9:9. doi: 10.3389/fnsyn.2017.00009
Keywords: microglia, synapses, brain development, synaptic function, synaptic pruning, neurodevelopmental disorders, infections, stress

\section{INTRODUCTION: MICROGLIA IN THE DEVELOPING BRAIN}

Microglia are commonly defined as the immune cells of the central nervous system (CNS). Along with their well-established role as immediate responders to injuries and infections, microglia also play important functions in the healthy brain, critically interacting with other cell types to provide support and to monitor neuronal circuits. A growing body of evidence indicates a central role of microglia in successful brain development and wiring, thus setting the stage for a new exciting subfield of research (extensively reviewed in Bessis et al., 2007; Ji et al., 2013b; Kettenmann et al., 2013; Sierra et al., 2014; Casano and Peri, 2015; Wu et al., 2015). Microglia critically contribute to many physiological processes, such as developmentally regulated neuronal apoptosis, neurogenesis (Wakselman et al., 2008; Cunningham et al., 2013; Mazaheri et al., 2014; Shigemoto-Mogami et al., 2014) and synaptic pruning in physiological and pathological conditions (Blinzinger and Kreutzberg, 1968; Paolicelli et al., 2011; Schafer et al., 2012; Kim et al., 2016). Furthermore, microglia assist with brain wiring through the promotion of synaptic formation and maturation (Hoshiko et al., 2012; Ueno et al., 2013; Miyamoto et al., 2016). Due to their roles in synaptic development and function, microglia are currently regarded as the fourth component of the 'quad-partite synapse', in addition to astrocytes and pre- and post-synaptic terminals (Paolicelli and Gross, 2011; Schafer et al., 2013). Microglia are extremely dynamic and responsive cells, and promptly respond to any homeostatic change (Davalos et al., 2005; Nimmerjahn et al., 2005). Pathological stimuli or brain insult profoundly affect microglial activity and switch their function from housekeepers to adaptive responders. The ensuing response perturbs microglial motility, morphology and function, 
thereby transiently compromising the execution of crucial physiological tasks. In the specific context of early brain maturation, it is becoming clear that severe perturbations of microglial activity, specifically during critical periods, might drastically delay the correct neuronal development and wiring of the brain. Here, we provide a summary of the recent literature supporting the importance of microglia for proper brain development. We focus on both environmental and genetic factors known to alter baseline microglial behavior, and discuss the consequent synaptic dysfunction and vulnerability to mental diseases.

\section{UNDERSTANDING MICROGLIAL FUNCTION BY DEPLETION APPROACHES}

\section{Microglia Depletion Models}

Removal of microglia during development has revealed a long-lasting impact on synaptic maturation and brain circuit formation. Both pharmacological and genetic methods have been adopted to deplete microglia from the brain. Common examples of pharmacological approaches to deplete microglia include the administration of toxic clodronate-containing liposomes (Buiting and Van Rooijen, 1994), and the inhibition of the Csf1 signaling pathway, crucial for microglial survival (Elmore et al., 2014; Squarzoni et al., 2014). Genetic depletion is achieved either by removing factors indispensable for microglial maturation and survival, such as PU.1 or CSF1R, or through the expression of 'suicidal genes', such as diphtheria toxin receptor (DTR) or viral thymidine kinase (HSVTK) under the control of specific microglial promoters, as $\mathrm{Cd} 11 \mathrm{~b}$ or $\mathrm{Cx} 3 \mathrm{cr} 1$ (see Table $\mathbf{1}$ ).

The advantage of pharmacological depletion methods is the possibility of treating any mouse strain, with a tight control on the timing of the treatment. However, clodronate liposomes do not cross the brain-blood barrier (BBB), thus requiring stereotaxic injections in the ventricles or in a selected brain structure. Because of the invasiveness of their administration, liposomes usage is not the method of choice for microglial depletion. Inhibitors of the CSF1R pathway, on the other hand, are easier to administer (via chow containing the inhibitor compound), but have significant side effects on other cells of the myeloid lineage, such as hematopoietic stems cells, macrophages, osteoclast, and mast cells (Thompson et al., 2015). In both cases, the pharmacological depletion is transient, since microglia are capable of rapidly repopulating the brain parenchyma within a few days of treatment (Elmore et al., 2014).

Genetic models such as constitutive knockout of critical transcription or survival factors (PU.1 KO, CSF1R KO, TGF $\beta$ $\mathrm{KO})$ have been largely used to achieve long-lasting microglial depletion. However, the serious complications arising from the removal of microglia during early development and the reduced rate of survival have substantially limited the use of such models. Inducible genetic microglial-specific CRE lines have been introduced as a method to overcome these developmental defects and achieve depletion at later developmental stages. However, the specificity of the employed promoters remains questionable. CX3CR1 in the brain is also expressed by perivascular, meningeal, and choroid plexus macrophages (Goldmann et al., 2016), whereas LysM and CD11b have even broader expression among other cell types of the myeloid lineage (Clausen et al., 1999; Ferron and Vacher, 2005). Although microglia represent the major population in the brain expressing these markers, the contribution of other cell types has to be considered.

\section{Effects of Microglia Depletion on Synapses}

All of these depletion models lead to considerable changes in synaptic function in vivo. The extent and the duration of such effects, as well as the neural circuits affected, are dependent upon the developmental stages in which the depletion occurs. In fact, different outcomes have been described following embryonic and post-natal depletion.

\section{Embryonic Depletion}

Depletion of embryonic microglia via CSF1R antibody treatment, and in the PU.1 knockout mouse model, resulted in the defective development of specific and important axonal tracts, as suggested by the abnormal outgrowth of tyrosine hydroxylase (TH)positive neurons dopaminergic axons in the forebrain, and by the axonal defasciculation in the dorsal corpus callosum (Pont-Lezica et al., 2014; Squarzoni et al., 2014). Early embryonic depletion (E6.5-E7.5) also led to the altered positioning of Lhx6-expressing interneurons in the cortical plate, thus indicating a critical impact on forebrain connectivity (Squarzoni et al., 2014).

\section{Post-natal Depletion}

Early post-natal depletion of microglia through injection of clodronate liposomes in the rat brain at post-natal day (PND) 2 and PND4 resulted in long-lasting impairments in anxiety, social and locomotor behavior (Nelson and Lenz, 2017). Short and transient microglia ablation in the Cd11b-DTR mouse line at PND3 is sufficient to induce significant neuronal cell death in cortical layer V (Ueno et al., 2013). Embryonic and early post-natal depletion of microglia have a profound effect on CNS architecture, significantly impacting on neuronal viability, neuronal migration, and axonal sprouting. Conversely, microglial depletion at later post-natal stages results in milder developmental effects, mostly involving the fine-tuning of synapses. Microglia depletion at either PND19 or PND30, by using inducible genetic models such as the $\mathrm{Cx} 3 \mathrm{cr} 1^{\mathrm{creER} /+}$; Rosa $26^{\mathrm{iDTR} /+}$ revealed a critical function of microglia in regulating baseline remodeling of post-synaptic dendritic spines in the motor cortex (Parkhurst et al., 2013). A significant decrease in both synapse elimination and formation was reported, associated with altered synaptic protein levels and impaired glutamatergic function (Parkhurst et al., 2013). Interestingly, depletion of microglia in adulthood in the same model induced reduction only of synapse formation, but not elimination, in motor learning induced-remodeling. This finding suggests that microglial-mediated pruning of synapses is confined to the first post-natal weeks, whereas the microglial role in supporting synapse formation is maintained across the lifespan (Parkhurst 
et al., 2013). Consistent with these data, selective microglia depletion in the hippocampus of adult mice by clodronate injections led to impaired spatial learning and social behavior defects. Interestingly, microglia depletion and behavioral effects were both reversible, consistent with a dynamic microglial role (Torres et al., 2016).

Ex vivo approaches have allowed further investigations into the role of microglia in refining synapses. Organotypic hippocampal slices depleted of microglia via clodronate liposomes treatment exhibited increased frequency of excitatory post-synaptic currents, consistent with higher synaptic density (Ji et al., 2013a). Replenishing the slices with microglia was sufficient to reverse the depletion effects, thus supporting a critical role for microglia in regulating the number of functional synapses (Ji et al., 2013a).

In summary, depletion models in pre- and post-natal periods demonstrate the essential role for microglia in the maintenance of synaptic function and provide evidence that microglia are critical for proper brain development.

\section{MICROGLIAL PERTURBATIONS DURING BRAIN DEVELOPMENT}

The research into synaptic development using depletion models has prompted further investigations to elucidate

TABLE 1 | Microglial depletion models.

\begin{tabular}{|c|c|c|c|c|c|}
\hline & $\begin{array}{l}\text { Targeted } \\
\text { signaling }\end{array}$ & Model & Timing & Reported effects & Publications \\
\hline \multirow[t]{3}{*}{$\begin{array}{l}\text { Pharmacological } \\
\text { depletion }\end{array}$} & Csf1R & $\begin{array}{l}\text { Anti-CSF1R Antibody: } \\
\text { treatment in utero }\end{array}$ & E6.5-E7.5 & $\begin{array}{l}\text { Defective development of } \\
\text { TH-positive dopaminergic } \\
\text { axons in the forebrain and } \\
\text { altered positioning of } \\
\text { Lhx6-expressing interneurons } \\
\text { in the cortical plate }\end{array}$ & $\begin{array}{l}\text { Squarzoni et al., 2014; } \\
\text { Hoeffel et al., } 2015\end{array}$ \\
\hline & Csf1R & $\begin{array}{l}\text { CSF1R kinase inhibitor } \\
\text { PLX3397: oral administration }\end{array}$ & $\begin{array}{l}2 \text { months } \\
12 \text { months } \\
18 \text { months }\end{array}$ & $\begin{array}{l}\text { No changes in motor or anxiety } \\
\text { behaviors. } \\
\text { Reduced escape latencies in } \\
\text { the Barnes maze training. } \\
\text { No changes in total brain } \\
\text { volume. }\end{array}$ & Elmore et al., 2014 \\
\hline & Cell survival & $\begin{array}{l}\text { Clodronate liposomes: } \\
\text { dichloromethylene- } \\
\text { bisphosphonate (Cl2MBP, } \\
\text { Clodronate) induces apoptosis } \\
\text { upon phagocytosis. } \\
\text { CNS injection }\end{array}$ & Different time points & $\begin{array}{l}\text { Long-lasting impairments in } \\
\text { anxiety, social and locomotor } \\
\text { behavior in rat }\end{array}$ & $\begin{array}{l}\text { Nelson and Lenz, 2017; } \\
\text { Buiting and Van } \\
\text { Rooijen, } 1994\end{array}$ \\
\hline \multirow[t]{5}{*}{ Genetic depletion } & Csf1R KO & Constitutive $\mathrm{KO}$ & $\begin{array}{l}\text { Early embryonic } \\
\text { depletion }\end{array}$ & $\begin{array}{l}\text { Increased neuronal density in } \\
\text { the cortex, elevated numbers of } \\
\text { astrocytes but reduced } \\
\text { numbers of oligodendrocytes }\end{array}$ & $\begin{array}{l}\text { Dai et al., 2002; } \\
\text { Ginhoux et al., 2010; } \\
\text { Erblich et al., } 2011\end{array}$ \\
\hline & PU.1 KO & Constitutive $\mathrm{KO}$ & $\begin{array}{l}\text { Early embryonic } \\
\text { depletion }\end{array}$ & $\begin{array}{l}\text { Defasciculation of dorsal } \\
\text { callosal axons. } \\
\text { Exuberant extension of } \\
\text { TH-positive axons into the } \\
\text { subpallium }\end{array}$ & $\begin{array}{l}\text { Iwasaki et al., 2005; } \\
\text { Kierdorf et al., 2013; } \\
\text { Pont-Lezica et al., } \\
\text { 2014; Squarzoni et al., } \\
2014\end{array}$ \\
\hline & $\begin{array}{l}\text { Cx3cr1cre }{ }^{E R} \\
\text { iDTR }\end{array}$ & $\begin{array}{l}\text { Inducible conditional depletion } \\
\text { upon diphtheria toxin } \\
\text { administration }\end{array}$ & $\begin{array}{l}\text { PND19, PND30, } \\
\text { PND60 } \\
\text { PND12-14 }\end{array}$ & $\begin{array}{l}\text { PND19 and PND30: decreased } \\
\text { spine formation and elimination. } \\
\text { PND60: decreased } \\
\text { learning-dependent spine } \\
\text { formation, but not elimination } \\
\text { PND12-14: increase in } \\
\text { pro-inflammatory cytokines and } \\
\text { chemokines in the cortex }\end{array}$ & $\begin{array}{l}\text { Parkhurst et al., 2013; } \\
\text { Bruttger et al., } 2015\end{array}$ \\
\hline & Cd11b-HSVtk & $\begin{array}{l}\text { Conditional depletion upon } \\
\text { ganciclovir treatment. } \\
\text { Thymidine kinase of herpes } \\
\text { simplex virus (encoded by } \\
\text { HSVtk) driven by the Cd11b }\end{array}$ & Adulthood & BBB damages & Heppner et al., 2005 \\
\hline & CNS-TGF $\beta$ KO & TGF $\beta$ depletion in the CNS & $\begin{array}{l}\text { Early embryonic } \\
\text { depletion }\end{array}$ & $\begin{array}{l}\text { Motor abnormalities around } \\
\text { PND100-120 }\end{array}$ & Butovsky et al., 2014 \\
\hline
\end{tabular}

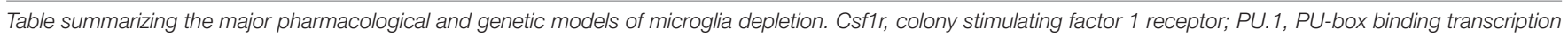
factor 1; CX3cr1, fractalkine receptor; iDTR, inducible diphtheria toxin; HSVtk, herpes simplex virus thymidine kinase; TGF $\beta$, transforming growth factor- $\beta$. 
the physiological function of microglia in refining neural circuits in development. Fundamental insights have come from studies in which the physiological microglial activity was perturbed either by environmental or genetic approaches.

Environmental stimuli such as stress (Merlot et al., 2008), infections (Boksa, 2010), diesel exhaust particles (Bolton et al., 2012, 2014) dietary intake (Giugliano et al., 2006) and un-physiological levels of glucocorticoids (Caetano et al., 2016) are well-characterized inducers of acute and chronic inflammatory responses. Importantly, all of these agents are known to increase the vulnerability to mental diseases characterized by profound synaptic defects (Pedersen and Mortensen, 2001; Volk et al., 2013; Drozdowicz and Bostwick, 2014). Human epidemiological data have shown clear associations between exposure to early-life adverse events and risk of neuropsychiatric conditions later in life (MacMillan et al., 2001), including depression (Agid et al., 1999; St Clair et al., 2015), autism spectrum disorders (ASDs) (Kinney et al., 2008) and psychosis (Varese et al., 2012). Similarly, prenatal infections occurring during the 1st and 2nd trimester of human pregnancy result in higher risk of schizophrenia (Brown et al., 2004) and ASD (Atladottir et al., 2010; Di Marco et al., 2016). These reports suggested a link between immune activation and synaptic development, however, the cellular mechanisms remained elusive.

Further investigations have attempted to dissect the differential contribution of systemic vs. brain immune response. Indeed, recent neuropathological studies in human postmortem brains have revealed strong microglial activation in neurodevelopmental disorders, such as schizophrenia (de Baumont et al., 2015; Sekar et al., 2016), and ASD (Voineagu et al., 2011; Gupta et al., 2014; Takano, 2015).

While the above studies provided only correlative evidence, data from genetically engineered animal models have demonstrated a causative role for microglia in the pathogenesis of neurodevelopmental disorders. Genetic manipulation affecting specific microglial function resulted in behavioral alterations reminiscent of obsessive-compulsive disorder (Chen et al., 2010; Zhan et al., 2014) and Rett Syndrome (Maezawa and Jin, 2010; Derecki et al., 2012), and in impaired functional brain connectivity reminiscent of autism and other neurodevelopmental disorders (Zhan et al., 2014).

Therefore, the collective evidence from human studies and microglial perturbation animal models (using both environmental and genetic approaches) indicate that altering microglial function during development contributes to the pathogenesis of neurodevelopmental disorders. Given the role of microglia in refining synaptic connectivity, an impaired cross-talk between microglia and synapses might represent a crucial mechanism linking microglial perturbation in early life to mental diseases susceptibility. Below, we review the current literature showing that environmental and genetic perturbations of microglial function during development have acute and long-lasting effects on synapses and behavior.

\section{Environmental Factors Modulating Microglial Activity}

Environmental factors, such as infections, stress and dietary intake are associated with synaptic dysfunction and are linked to increased risk for neurodevelopmental/psychiatric disorders (Marques et al., 2013, 2015; Knuesel et al., 2014; Ajdacic-Gross et al., 2016; Estes and McAllister, 2016). Importantly, all of the above factors have been shown to activate the immune system during early brain development. Recent studies also showed that microglia-synapse contacts are strongly modulated by neural activity, highlighting sensory deprivation as a further regulator of microglial activity. Burgeoning evidence suggests that microglia substantially contribute to the environmental-mediated synaptic defects.

\section{Infections}

Both viral and bacterial infections have been shown to alter behavior and cognition in experimental animals when administered during critical developmental periods (Boksa, 2010; Meyer, 2014), suggesting profound synaptic remodeling. Importantly, the initial systemic immune response elicited by the infection is followed by a microglial-mediated inflammatory reaction in the brain (Turrin et al., 2001; Puntener et al., 2012). Therefore, there is a growing interest in the role of microglia in infection-mediated synaptic remodeling during development.

\section{Viral infection}

In a seminal paper, maternal infection of experimental rodents with the influenza virus resulted in deficits in a variety of behavioral displays, including open-field, prepulse inhibition, object recognition and social behavior in the adult offspring (Shi et al., 2003). This study was the first to establish a causal relationship between prenatal viral infection and psychiatric and neurological symptoms in adulthood, which had been previously suggested by a plethora of epidemiological studies (Brown, 2012).

The most widely used model in experimental rodents is the prenatal injection of viral mimetic polyriboinosinicpolyribocytidilic acid (Poly I:C). Poly I:C, a synthetic analog of double-stranded RNA that is recognized as foreign by the rodent immune system, efficiently stimulates an immune response via TLR3 activation. In the mouse species, prenatal immunological stimulation with Poly I:C in early/middle gestation leads to a spectrum of behavioral abnormalities in adulthood, strongly depending on the timing of the infection. Mid-gestational (E9) Poly I:C exposure leads to impairments in pre-pulse inhibition of the acoustic startle reflex and in latent inhibition (Meyer et al., 2005), considered relevant to schizophrenia and ASD. On the other hand, impairments in cognition are elicited following Poly I:C exposure at late gestation (E17) (Meyer et al., 2006). At the molecular level, changes in both pre-and post-synaptic elements, with altered NMDA receptor composition (Forrest et al., 2012), reduced PSD95 and SynGAP density (Giovanoli et al., 2016b), as well as reduced synpatophysin elements (Oh-Nishi et al., 2010; Giovanoli et al., 2016b) have been described in the adult offspring of Poly I:C infected dams. In addition, prenatal Poly I:C injection has been linked to the onset of white matter abnormalities in corticostriatal areas, including myelin-related transcriptional and 
epigenetic changes, and alterations of myelin water fraction in adulthood (Richetto et al., 2016).

Both acute and chronic immune responses are observed following prenatal Poly I:C injection. Acutely, Poly I:C causes a transient increase in inflammatory mediators in maternal blood and fetal brain (Gilmore et al., 2005; Forrest et al., 2012; Smolders et al., 2015). The cellular origin of these inflammatory mediators is still a matter of debate. Indeed, Pratt et al. (2013) have reported an acute increase in cytokine expression by fetal microglia, suggesting that microglia might be the source of inflammatory cytokines in the brain of prenatally Poly I:C injected mice. However, other authors did not observe acute changes in microglial density or expression of inflammatory markers following prenatal exposure to Poly I:C, in spite of systemic inflammation in the dams (Smolders et al., 2015).

While the inflammatory response in the fetal brain is wellestablished, its persistence in the post-natal brain is highly controversial. In some studies inflammation was shown to almost completely subside in adulthood, with normal cytokine plasma levels, unaltered microglial density and moderate increase in IL-1 $\beta$ levels in the hippocampus of adult offspring of infected dams at E9 (Giovanoli et al., 2016b) and E14 (Mattei et al., 2014). In others, Poly I:C injections led to sustained cytokine level changes that lasted into adulthood. A comprehensive study by Garay et al. (2013) reported long-lasting, region-specific inflammatory changes in offspring of Poly I:C injected dams (E12.5), across five post-natal ages. In cortical regions, most cytokines were altered at all of the ages analyzed, following a pattern of elevation at birth, decreasing during the early postnatal weeks (PND7-PND30), and elevation again in adulthood (P60) (Garay et al., 2013). Interestingly, cytokine levels in the hippocampus showed a distinct pattern, with mixed directionswitches across ages (Garay et al., 2013). All of the changes in the brain occurred independently of serum cytokine alterations, in the absence of immune cell infiltration, and with no increase in microglia density (Garay et al., 2013).

Importantly, the Poly I:C-induced inflammatory response during development is sufficient to induce long-lasting changes in microglial expression profile and function, but not in microglial numbers. Indeed, recent global transcriptional data have revealed that Poly I:C injection at E14.5 interferes with development of early microglia, shifting them into a more advanced developmental stage (Matcovitch-Natan et al., 2016).

Such early interference has long-lasting effects on microglial function, producing 'primed' microglia, with increased susceptibility to activation. In fact, a 'second hit' (i.e., sub chronic unpredictable stress) can elicit an exacerbated hippocampal microglial response (with increased soma size, CD68 and IL-1 $\beta$ expression) in the offspring of Poly I:C injected mothers as compared to controls (Giovanoli et al., 2016a).

The molecular mediators of Poly I:C effects on both the structure and the function of the developing CNS are not fully elucidated; however, inflammatory cytokines, including IL- 6 and IL-1 $\beta$, are likely to be crucial players. IL- 6 release has been shown to mediate the behavioral effects of viral prenatal infections. Injection of IL-6 into pregnant dams at E12 induced pre-pulse inhibition and latent inhibition deficits in adulthood, similar to Poly I:C treatment. Importantly, genetic or pharmacological blockade of IL-6 fully prevented Poly I:C-induced gene expression changes and behavioral alterations (Smith et al., 2007). In addition, recent evidence suggests that IL-1 $\beta$ might be involved in the effects of prenatal Poly I:C on white matter in adulthood. Intraperitoneal injections of IL-1 $\beta$ in newborn mice (PND1-PND4) is sufficient to largely disrupt the developmental program of white matter (Favrais et al., 2011), in line with the observations of Richetto et al. (2016) in Poly I:C-challenged offspring. Recent studies found that the anti-inflammatory drug minocycline prevented the effect of prenatal Poly I:C administration on behavior in adulthood (Mattei et al., 2014; Zhu et al., 2014; Giovanoli et al., 2016a), further indicating a causative relationship between inflammation and synaptic dysfunction.

\section{Bacterial infections}

Systemic injections into pregnant dams or pups of the gramnegative bacterial component lipopolysaccharide (LPS), or inactivated Escherichia coli, are commonly used models to study central effects of pre- and early post-natal bacterial infections.

Maternal immune activation with LPS resulted in increased anxiety (Hava et al., 2006) and decreased social behavior in the male offspring (Kirsten et al., 2010), phenotypes relevant to ASD. The behavioral alterations were accompanied by glutamatergic remodeling in the hippocampus, with increased AMPAR contribution to excitatory neurotransmission (Roumier et al., 2008) and increased spine density (Fernandez de Cossio et al., 2016).

A prenatal LPS injection caused acute and long-lasting effects on microglia. LPS administration at E15-16 resulted in immediate up-regulation of iNOS expression in microglia in the embryos (Cunningham et al., 2013), indicating acute activation. Such alterations persist during early post-natal periods, with increased microglial density in hippocampus (Roumier et al., 2008) and substantia nigra (Ling et al., 2006) of prenatally LPS-injected mice analyzed at PND0. Importantly, up-regulation of OX $-6^{+}$microglial cells in the substantia nigra was shown to be sustained until PND84, and to be further exacerbated by a second hit of LPS injection in adulthood, suggesting enduring effects on prenatal infection on microglia (Ling et al., 2006).

Several reports support the notion that prenatal bacterial infection interferes with specific physiological functions of microglia during development. Interestingly, synaptic remodeling induced by LPS prenatal injection is phenocopied in models of microglial depletion, pointing to a loss of homeostatic function.

Roumier et al. $(2004,2008)$ have shown that mice carrying a loss of function mutation in the DAP12 gene (a signaling protein transiently expressed by microglia at birth) recapitulate the glutamatergic remodeling seen with LPS injection. More recently, Squarzoni et al. (2014) have shown that maternal immune activation with LPS induces alterations in the laminar positioning of $\mathrm{LHX}_{-} 6^{+}$interneurons similar to what was observed via depletion of microglia. The exact mechanisms by which prenatal bacterial infection interferes with synapse-microglial interaction 
are still unclear, but recent evidence suggests a role for CX3CR1 signaling. In fact, prenatally LPS-infected rats display reduced hippocampal CX3CR1 expression along with increased spines in the dentate gyrus (Fernandez de Cossio et al., 2016). It could be speculated that the LPS induced-downregulation of the CX3CR1 receptor might alter the physiological pruning of synapses. However, further work is required to test this hypothesis.

Early post-natal infection with LPS has been shown to induce anxiety-like behaviors (Sominsky et al., 2012) and impaired cognitive function in adult rats (Pang et al., 2016). LPS injection in rat pups at PND5 results in acute microglial activation with increased numbers of $\mathrm{Ibal}^{+}$cells in the hippocampus and up-regulation of both M1 and M2 markers (Smith et al., 2014; Pang et al., 2016). Iba1 ${ }^{+}$cell numbers normalized by PND21, but M1 marker expression was still subtly altered (Smith et al., 2014). Furthermore, increased Ibal immunoreactivity was observed in the dentate gyrus of PND85 neonatally infected rats (Sominsky et al., 2012). These results suggest that behavioral deficits might be due to both acute and long-lasting effects of neonatal LPS injection on microglia.

Escherichia coli administration in PND4 rats induced mild behavioral perturbations in adulthood, including hippocampaldependent deficits in the reversal phase of the Morris Water Maze task (Williamson and Bilbo, 2014) and impaired motor coordination (Lieblein-Boff et al., 2013). Effects on inflammatory markers are short and transient in this model, with up-regulation of IL-1 $\beta$ and CD11b expression in the hippocampus that normalizes by $72 \mathrm{~h}$ post-injection (Bilbo et al., 2005). However, the immune system of post-natally $E$. coli-infected mice has been shown to be primed, and displays an exacerbated response to a 'second hit' with a low-dose of LPS, in adulthood (Bilbo et al., 2005; Williamson et al., 2011). Importantly, the immune alterations caused by the 'second hit' with LPS were accompanied by severe memory impairments, indicating a crucial role for primed microglia in mediating cognitive deficits. Importantly, blocking microglial activation with minocycline or caspase 1 inhibitor immediately before a 'second hit' of LPS in adulthood prevented the appearance of cognitive deficits in neonatally infected rats (Bilbo et al., 2005; Williamson et al., 2011). It is crucial to note that $E$. coli injections at later post-natal time points, such as PND30, do not result in exacerbated microglial response or altered behavioral display following a 'second hit' with LPS in adulthood (Bilbo et al., 2006). These findings further support the notion that the acquired vulnerability to the second hit is not a general sensitizing event, but it is strictly dependent on the developmental stage in which the first infection occurs (Bilbo and Schwarz, 2009, 2012).

\section{Stress}

Intermittent and unpredictable maternal separation, as well as stressful manipulations of pregnant dams (via restraint, sleep deprivation, or light exposure), are common experimental models of early-life adverse events and developmental stress. In striking similarity with human data, the early-stressed pups go on to develop syndromes later in life that resemble depression (Mintz et al., 2005; Ruedi-Bettschen et al., 2005), and anxiety (Vallee et al., 1997); for a review (Nishi et al., 2014). In recent years an increased interest has arisen on the role of microglia in earlystress-induced remodeling of cortical and hippocampal synapses. Indeed, different models of perinatal stress have been shown to induce both acute and long-lasting effects on microglia activity.

Prenatally stressed mice displayed higher numbers of ramified microglia in several brain regions analyzed at PND1, including parietal, entorhinal and frontal cortices, septum, basal ganglia, thalamus, medulla oblongata, and internal capsula (GomezGonzalez and Escobar, 2010). Primary cultures of microglia isolated from prenatally stressed rats showed increased release of pro-inflammatory cytokines, including IL- $1 \beta$, IL-18, TNF- $\alpha$ and IL-6, and reduction of IGF-1 (Slusarczyk et al., 2015). Such cytokines, and in particular IL-18 and TNF- $\alpha$, were shown to directly increase neuronal excitability via up-regulation of voltage-activated $\mathrm{Na}^{+}$currents (Igelhorst et al., 2015; Klapal et al., 2016). The microglial effects have been shown to be mostly transient, with microglia morphology returning to normal by PND10 (Gomez-Gonzalez and Escobar, 2010). However, prenatally stressed mice, when examined in adulthood, showed hippocampal microglial alterations, with a higher density of Iba ${ }^{+}$cells, enlargement of soma, increased pro-inflammatory expression and heightened response to a second hit with LPS injection (Diz-Chaves et al., 2012, 2013). Similar findings were reported in rats, with adult prenatally stressed subjects displaying increased expression of microglial activation markers, and increased $\mathrm{Iba1}^{+}$microglial density in the hippocampus and frontal cortex (Slusarczyk et al., 2015; Zhao et al., 2015). These results suggest that prenatal stress can induce long-lasting effects on microglial function in the hippocampus and cortex.

More subtle effects have been observed in models of early post-natal stress. Maternal deprivation during the first 2 weeks of life was associated with acute effects on hippocampal microglia, including larger soma size, increased release of IL-1 $\beta$ (Roque et al., 2016) and increased microglial surface area (Delpech et al., 2016). Delpech et al. (2016), however, reported that alterations in microglial morphology were transient and parameters normalized later at PND28. Analysis of PND28 hippocampi from mice that experienced early stress revealed that, in spite of apparently normal morphology, microglia had altered transcriptional activity of PU1, Creb and Sp1, resulting in gene expression changes and increased phagocytic activity (Delpech et al., 2016). Long-lasting effects of earlylife stress were also reported in other brain areas. Increased microglia motility was observed in the sensorimotor cortex of adult mice that had experienced maternal deprivation (Takatsuru et al., 2015). In this study, the authors observed a positive correlation between microglial motility and nociceptive threshold, suggesting a functional link between altered microglia activity during development and synaptic plasticity in adulthood.

Minocycline treatment can efficiently prevent behavioral deficits that follow prenatal stress, normalizing, in parallel, microglial expression of pro- and anti-inflammatory markers in the hippocampus (Zhao et al., 2015). These findings suggest that long-lasting microglial alterations might mediate the behavioral consequences of early stress.

The link between microglia and stress has been convincingly shown in adult mice. Anti-inflammatory treatment ameliorated 
chronic stress-induced behaviors (Hinwood et al., 2012, 2013; Kreisel et al., 2014; Fuertig et al., 2016). Furthermore, mice lacking the microglial-specific CX3CR1 receptor showed resilience to stress-induced depressive behavior (Hellwig et al., 2016; Milior et al., 2016). Therefore, microglia can play a crucial role in mediating vulnerability to stress and its downstream effects on synaptic circuits. However, the molecular mechanisms by which microglia mediate synaptic and behavioral changes in early-stress models are far from been understood.

\section{Dietary Intake}

Imbalance in dietary intake has been convincingly associated with cognitive function. High-fat diet (HFD) consumption is associated with cognitive impairment, increased aggression and altered social- and reward-related behaviors in mice (HilakiviClarke et al., 1996; Pistell et al., 2010; Takase et al., 2016). A mouse model of n-3 polyunsaturated fatty acids (PUFAs) deficiency resulted in defective spatial learning and memory tasks, with increased depressive-like behavior (Larrieu et al., 2012; Moranis et al., 2012).

Both the imbalance in PUFAs content and the long-term exposure to HFD lead to dysregulation of inflammatory processes (Ortega et al., 1997; Pistell et al., 2010; Sharma et al., 2012; Valdearcos et al., 2014; Baufeld et al., 2016; Guillemot-Legris et al., 2016; Gzielo et al., 2016). Interestingly, docosahexaenoic acid (DHA), one of the most abundant PUFAs in the brain and a potent immunomodulator, was shown to prevent LPS-induced cytokine production in microglia, by directly inhibiting the surface presentation of CD14 and TLR4 (De Smedt-Peyrusse et al., 2008). A growing literature provides evidence for a direct role of DHA in regulating microglial activity (Antonietta Ajmone-Cat et al., 2012; Chen et al., 2014; Chang et al., 2015; Baufeld et al., 2016; Hao et al., 2016; Hopperton et al., 2016; Tremblay et al., 2016).

The effects of dietary imbalance during development have been recently investigated. Dietary intake was shown to act as a modulator of microglial behavior in the perinatal brain in studies where female mice were fed throughout gestation and lactation with n-3 PUFAs deficient or a control diet. Mice raised under n-3 PUFAs deficiency exhibited altered levels of microglial phenotypic markers and defective microglia motility at PND21. This defective microglial activity was associated with increased pro-inflammatory cytokine expression, and altered expression of plasticity-related genes in neurons (Madore et al., 2014). Overall these findings indicate that dietary intake, specifically in relation to PUFA content, might drastically impact on microglial properties. The consequent microglial-mediated increase in inflammation, when occurring early in development, may contribute to neurodevelopmental disorders (Bolton and Bilbo, 2014).

The mechanisms linking dietary intake to microglial activation are beginning to be elucidated. Erny et al. (2015) have recently shown that gut microbiota control maturation and function of microglia, possibly via release of short-chain fatty acids (SCFAs: microbiota-derived bacterial fermentation products). Germ-free mice and antibiotic treated mice displayed altered microglia expression and morphology consistent with immature phenotype; the results were phenocopied in mice deficient for the SCFA receptor FFAR2 (Erny et al., 2015). Hence, evidence exist that dietary intake can modulate microglial activity, and at least some of this interaction might be mediated via host microbiota (Smith, 2015; Campos et al., 2016; Erny et al., 2017).

\section{Neural Activity-Dependent Modulation of Microglia}

Increasing neural activity by pharmacological blocking of inhibition, by AMPAR or by NMDAR activation (Fontainhas et al., 2011; Dissing-Olesen et al., 2014), but not by electrical stimulation (Wu and Zhuo, 2008), results in enhanced microglial motility and extension of microglial processes. Conversely, GABAergic activation leads to a reduction in microglial motility (Fontainhas et al., 2011). Many studies support the theory that microglia-synapse contacts and engulfment of synaptic material are strongly modulated by neural activity. Apposition between microglia and synaptic terminals increase following neuronal activity, and correlate with higher rate of synaptic elimination upon ischemia (Wake et al., 2009) and in an experience-dependent manner (Tremblay et al., 2010). Similarly, microglia-mediated engulfment of synaptic inputs in the early developing dorsal lateral geniculate nucleus is regulated by neural activity: increasing upon inhibition with tetrodotoxin or stabilizing with forskolin activation (Schafer et al., 2012).

Indeed, environmental manipulations that either increase or decrease neuronal activity have been shown to impact on the microglial phenotype and its interaction with dendritic spines. Environmental enrichment (EE) is a well-established experimental paradigm of neuronal stimulation, resulting in a brain derived neurotrophic factor (BDNF)-dependent increase in the number of spines, physical rewiring of the brain and improvement in several cognitive domains (van Praag et al., 2000). Exposure to an enriched environment has also been shown to promote microglial branching (Xu et al., 2016) and profoundly affect neuroimmune functions in the hippocampus (Williamson et al., 2012). Importantly, LPS injection abrogated the EE-induced increase in BDNF production, suggesting that microglia are not simply bystanders, but are actively involved in the beneficial effects of EE (Williamson et al., 2012). On the other hand, deprivation of a specific sensory input (e.g., vision) during critical developmental periods also results in dramatic neuronal remodeling at both the synaptic and circuit levels. Microglia have been shown not only to respond to sensory deprivation, but also to mediate some of its neuronal effects. Following dark adaptation (a paradigm resulting in increased spine motility and turnover in primary visual cortex, Majewska and Sur, 2003), Tremblay et al. (2010) found subtle changes in the behavior of microglia in the primary visual cortex of juvenile mice. The observed changes included an expansion of microglial processes, an increased occurrence of cellular inclusions (suggesting phagocytosis), an increased frequency of contact with synaptic clefts, and an increased apposition with synaptic elements, with overall reduced motility (Tremblay et al., 2010). These results are largely confirmed by Sipe et al. (2016) in 
a model of monocular deprivation (MD), where sensory inputs are abrogated from one eye only. In this model, the authors observed an increase in the contacts between microglia and spines, occurring at day 1 post MD. This increased interaction was followed by active engulfment of synaptic material by microglia 4 days after MD. These data suggest that microglia are capable of sensing the altered neuronal activity and can respond by remodeling synapses (Sipe et al., 2016). Importantly, in MD models, neuron-microglia interaction was shown to significantly contribute to the functional plasticity that follows sensory deprivation. In fact, $\mathrm{MD}$ normally results in the full shift of ocular dominance from the closed eye to the open eye within 2 days (Wiesel and Hubel, 1963). However, this effect was abrogated in mice either lacking the P2Y12 receptor, or receiving a specific P2Y12 inhibitor (Sipe et al., 2016). Since this receptor is exclusively expressed in CNS microglia, crucially mediating the neuron-microglia cross-talk (Sasaki et al., 2003; Haynes et al., 2006), the above results indicate that sensory deprivation requires microglia to rewire the visual cortex. How P2Y12 modulates ocular dominance, and whether this is mediated via spine remodeling, remains to be elucidated.

A reciprocal regulation between microglia and neural activity has also been shown in the zebrafish optic tectum, where microglia contacts with active neurons are more frequent, and result in neuronal silencing in a contact-dependent mechanism (Li et al., 2012). These findings indicate that neural activity is shaping brain connectivity also through the critical contribution of microglia.

\section{Genetic Factors Modulating Microglial Activity}

The use of genetically modified mouse models and the recent advent of Cre lines selective for microglia have been instrumental in dissecting the role of specific genes in modulating microglial activity. Altering the function of genes involved in the regulation of key executive microglial tasks, such as motility, migration, phagocytosis and cytokine release, affects a broad spectrum of microglial-mediated cellular processes, which occur in the developing brain. Several such alterations are linked to the onset of behavioral symptoms reminiscent of neurodevelopmental and psychiatric disorders in humans, indicating a key role for microglia in such diseases.

DAP12 is a transmembrane protein associated with the TREM2 receptor, with specific microglial expression, and is up-regulated in the developing brain (Aoki et al., 2000; Roumier et al., 2008). Mouse models expressing a mutated form of DAP12 lacking the expression of the functional protein were one of the first examples of selective microglia manipulation significantly impacting on synaptic function. DAP12 KO mice displayed defective mIPSC (miniature inhibitory post-synaptic currents), impaired AMPAR accumulation at the post-synaptic site, and showed a drastic reduction in BDNF-specific TrkB receptor. Such impairments translated into defective synaptic transmission, thus likely to affect brain wiring (Kaifu et al., 2003; Roumier et al., 2004). In addition, the positioning of Lh6-expressing interneurons in the cortical plate of E18.5 embryos and P7 mice was impaired in the DAP12 KO models, suggesting that microglia may support the functioning of neural circuits by contributing to the maintenance of inhibitory/excitatory balance (Squarzoni et al., 2014). Adult DAP12 KO mice displayed phenotypes relevant to schizophrenia and ASD, such as reduced startle reflex in response to acoustic stimuli and reduced prepulse inhibition, suggesting an impairment of sensorimotor gating (Kaifu et al., 2003).

CX3CR1 is a $\mathrm{G}_{\mathrm{i}}$-protein coupled receptor, encoded by the $C x 3 c r 1$ gene, expressed mostly by microglia in the brain (Jung et al., 2000; Mizutani et al., 2012). Its ligand CX3CL1, also known as fractalkine, is on the other hand largely expressed in neurons (Tarozzo et al., 2003). The fractalkine signaling has been extensively investigated in recent years, with accumulating evidence supporting its role in controlling fundamental microglia functions (Limatola and Ransohoff, 2014; Paolicelli et al., 2014; Arnoux and Audinat, 2015). The loss of the fractalkine signaling significantly affects basic microglial properties, such as voltage-dependent $\mathrm{K}^{+}$currents, processes ramification and ATP-induced migration (Pagani et al., 2015). The brains of $\mathrm{Cx} 3 \mathrm{cr} 1 \mathrm{KO}$ embryos displayed extensions of $\mathrm{TH}$-positive dopaminergic neurons, selectively in the subpallium, but not in the midbrain, and showed defective positioning of Lh6-expressing interneurons in the neocortical plate (Squarzoni et al., 2014). Cx3cr1 KO brains at early post-natal stages also showed a significant increase in cell death in the cortical layer $\mathrm{V}$, phenocopying the effects of microglia depletion via DTR expression (Ueno et al., 2013). Hoshiko et al. (2012) showed that the lack of the Cx3cr1 was associated with delayed maturation of the developing synapses in the barrel cortex, specifically affecting the NMDAR composition. These findings confirmed previous studies reporting causal effects on synaptic plasticity with modulation of Cx3Cl1/Cx3cr1 signaling (Ragozzino et al., 2006; Maggi et al., 2011; Rogers et al., 2011). Cx3cr1 KO mice displayed a transient reduction in microglial numbers in the developing hippocampus, and showed defective synaptic pruning, resulting in synaptic deficits and long-lasting impairments in social behavior and brain connectivity (Paolicelli et al., 2011; Zhan et al., 2014). The lack of fractalkine signaling was associated with reduced levels of free Insulin-like Growth Factor 1 (IGF1) in the mouse cortex at PND5, ultimately affecting the survival of corticospinal and callosal neurons (Ueno et al., 2013). Overall, these observations indicate that the defective microglial function induced by the lack of $\mathrm{Cx} 3 \mathrm{cl} 1 / \mathrm{Cx} 3 \mathrm{cr} 1$ signaling significantly affects brain development, with long-lasting consequences on neural circuits and brain function.

BDNF Microglial contribution to synaptic plasticity and function has been elegantly demonstrated through an inducible conditional knockout (cKO) mouse line, where BDNF was selectively depleted from microglia (Parkhurst et al., 2013). $\mathrm{BDNF}$ influences a large variety of cellular processes, ranging from survival, to apoptosis, cellular morphology, and synaptic 
TABLE 2 | Environmental factors shown to affect synapses and behavior via microglia.

\begin{tabular}{|c|c|c|c|c|}
\hline & Model & Timing & Reported effects in adulthood & Publications \\
\hline \multirow[t]{5}{*}{ Infections } & Viral (Poly I:C) & Prenatal & IL-6 mediated behavioral alterations & Smith et al., 2007 \\
\hline & & & IL-1 $\beta$ mediated white matter disruption & Favrais et al., 2011 \\
\hline & & & $\begin{array}{l}\text { Minocycline prevents Poly I:C-induced } \\
\text { behavioral abnormalities }\end{array}$ & $\begin{array}{l}\text { Mattei et al., 2014; Zhu } \\
\text { et al., 2014; Giovanoli } \\
\text { et al., 2016a }\end{array}$ \\
\hline & Bacterial (LPS) & Prenatal & $\begin{array}{l}\text { Reduced hippocampal CX3CR1 } \\
\text { expression; increased spines } \\
\text { hippocampus }\end{array}$ & $\begin{array}{l}\text { Fernandez de Cossio } \\
\text { et al., } 2016\end{array}$ \\
\hline & Bacterial (E. coli) & Post-natal & $\begin{array}{l}\text { Primed microglia with exacerbated } \\
\text { response to second hit; minocycline } \\
\text { and caspase } 1 \text { inhibitor prevent the } \\
\text { appearance of cognitive deficits in } \\
\text { neonatally infected mice subjected to a } \\
\text { second hit }\end{array}$ & $\begin{array}{l}\text { Bilbo et al., 2005; } \\
\text { Williamson et al., } 2011\end{array}$ \\
\hline \multirow[t]{2}{*}{ Stress } & Sleep deprivation & Prenatal & Minocycline prevents behavioral deficits & Zhao et al., 2015 \\
\hline & Maternal deprivation & Early post-natal & $\begin{array}{l}\text { Increased microglia motility correlates } \\
\text { with nociceptive threshold }\end{array}$ & Takatsuru et al., 2015 \\
\hline Dietary imbalance & n-3 PUFAs deficient diet & $\begin{array}{l}\text { Prenatal and } \\
\text { early post-natal }\end{array}$ & $\begin{array}{l}\text { Defective microglia motility associated } \\
\text { with altered expression of } \\
\text { plasticity-related genes in neurons }\end{array}$ & Madore et al., 2014 \\
\hline Sensory deprivation & Monocular deprivation & Post-natal & $\begin{array}{l}\text { Mice lacking P2Y12 receptor do not } \\
\text { display full shift of ocular dominance }\end{array}$ & Sipe et al., 2016 \\
\hline
\end{tabular}

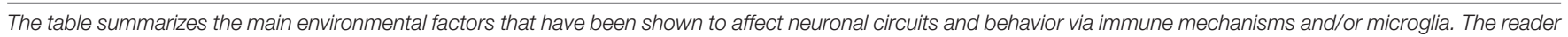
should consult Section "Environmental Factors Modulating Microglial Activity" for details and discussion.

TABLE 3 | Microglial genes shown to affect synapses and behavior.

\begin{tabular}{|c|c|c|c|c|}
\hline & $\begin{array}{l}\text { Protein } \\
\text { manipulated }\end{array}$ & KO type & Reported effects & Publications \\
\hline \multirow[t]{2}{*}{$\begin{array}{l}\text { Transmembrane } \\
\text { proteins }\end{array}$} & DAP12 & Constitutive & $\begin{array}{l}\text { Reduced startle reflex to acoustic stimuli and } \\
\text { reduced pre-pulse inhibition; Defective mIPSCs; } \\
\text { impaired AMPA receptor accumulation: reduction in } \\
\text { TrkB receptors; defective synaptic transmission; } \\
\text { defective positioning of Lh6-expressing } \\
\text { interneurons in cortical plate of E18.5 }\end{array}$ & $\begin{array}{l}\text { Kaifu et al., 2003; } \\
\text { Roumier et al., 2004; } \\
\text { Squarzoni et al., } 2014\end{array}$ \\
\hline & CX3CR1 & Constitutive & $\begin{array}{l}\text { Defective positioning of Lh6-expressing } \\
\text { interneurons in cortical plate of E18.5; increased } \\
\text { cell death in cortical layer V; delayed maturation of } \\
\text { synapses in barrel cortex; defective synaptic } \\
\text { pruning and long-lasting impairments in social } \\
\text { behavior and brain connectivity }\end{array}$ & $\begin{array}{l}\text { Ragozzino et al., 2006; } \\
\text { Maggi et al., 2011; } \\
\text { Paolicelli et al., 2011; } \\
\text { Rogers et al., 2011; } \\
\text { Ueno et al., 2013; } \\
\text { Squarzoni et al., 2014; } \\
\text { Zhan et al., 2014 }\end{array}$ \\
\hline \multirow[t]{2}{*}{ Complement } & C1q & Constitutive & Enhanced connectivity and epilepsy & Chu et al., 2010 \\
\hline & C3 or CR3 & Constitutive & Decreased synaptic engulfment & Schafer et al., 2012 \\
\hline Trophic factors & BDNF & $\begin{array}{l}\text { Inducible conditional } \\
\mathrm{KO} \text { in } \\
\text { CX3CR1-expressing } \\
\text { cells }\end{array}$ & $\begin{array}{l}\text { Altered synaptic protein levels; impaired spine } \\
\text { formation and elimination; lack of training-induced } \\
\text { improvement in motor behavior performance }\end{array}$ & Parkhurst et al., 2013 \\
\hline \multirow{2}{*}{$\begin{array}{l}\text { Phagocytosis and } \\
\text { autophagy-related } \\
\text { proteins }\end{array}$} & Progranulin & Constitutive & $\begin{array}{l}\text { Increased synaptic pruning of C1q-tagged } \\
\text { synapses }\end{array}$ & Lui et al., 2016 \\
\hline & $\begin{array}{l}\text { ATG7 } \\
\text { (autophagy } \\
\text { related gene 7) }\end{array}$ & $\begin{array}{l}\text { Conditional in } \\
\text { lyzsozyme } \\
\text { M-expressing cells }\end{array}$ & $\begin{array}{l}\text { Increased dendritic spines; increased synaptic } \\
\text { markers; long-lasting effects in sociability and } \\
\text { repetitive behaviors }\end{array}$ & Kim et al., 2016 \\
\hline
\end{tabular}

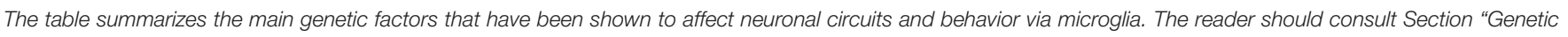
Factors Modulating Microglial Activity" for details and discussion. 


\section{Perturbation of microglial activity during early development: hypothetical model}

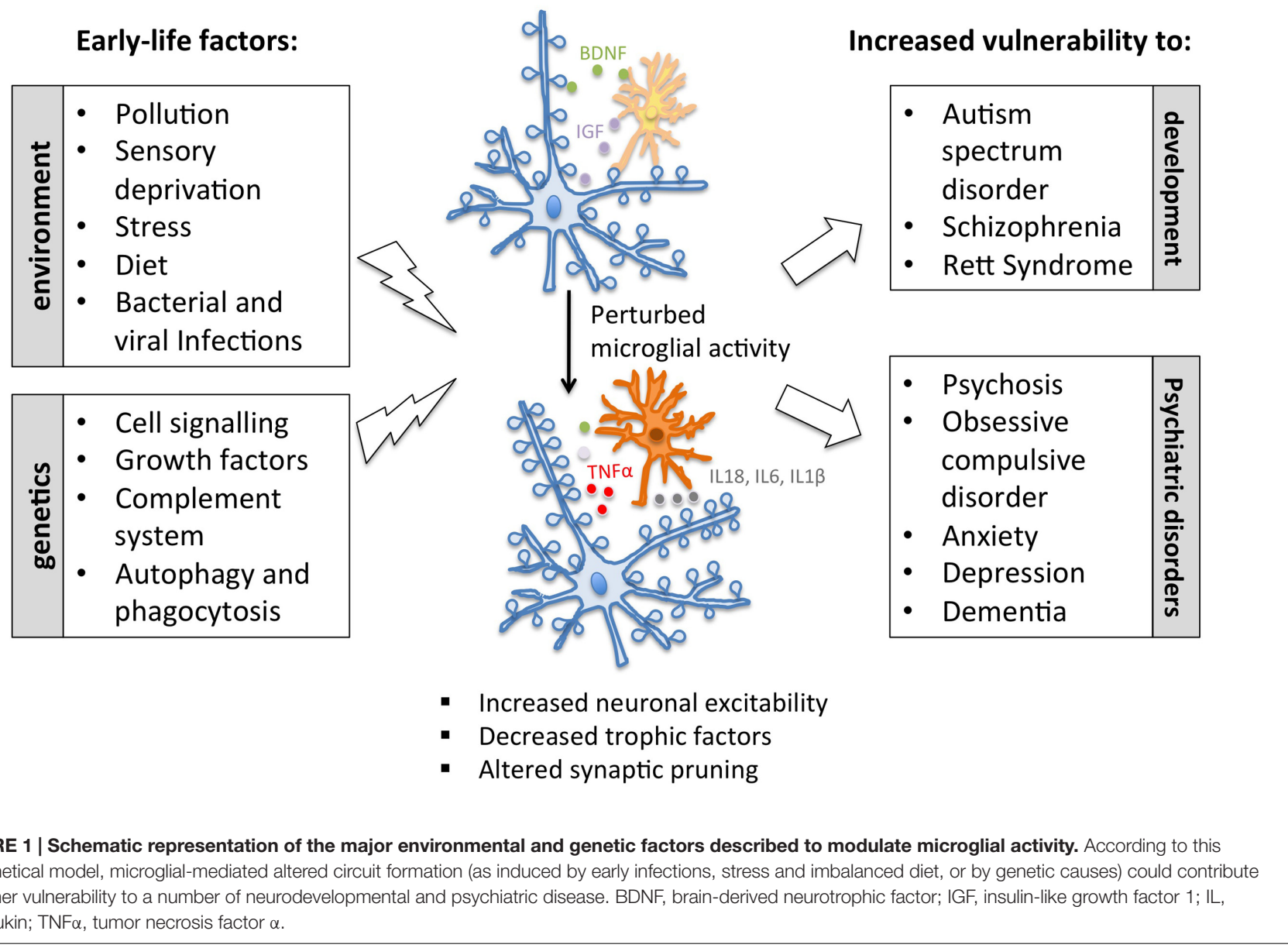

plasticity (Hohn et al., 1990; Lu et al., 2005; Park and Poo, 2013). Along with neurons, microglia also represent a source of neurotrophin in the brain (Elkabes et al., 1996; Elkabes et al., 1998; Coull et al., 2005; Trang et al., 2011). Mice lacking microglial BDNF displayed altered synaptic protein levels and impaired spine formation during motor learning tasks, which resulted in the absence of training-induced improvement in motor behavior performance, suggesting an important role for microglial derived BDNF in modulating synaptic plasticity (Parkhurst et al., 2013).

The Complement system is a complex innate immune surveillance system, with important functions in inflammation, pathogen defense and host homeostasis (Zabel and Kirsch, 2013; Merle et al., 2015). Complement molecules such as C1q and C3, are up-regulated in the early post-natal brain, and have been implicated in synaptic remodeling during the development of the retinogeniculate system (Stevens et al., 2007). C1q and C3, closely apposed to synapses, work as 'eat-me' signals for the synaptic terminals to be removed. Loss of function approaches, such as genetic knockout mouse lines, resulted in increased synapse number, suggesting that the absence of such molecules could impair synaptic pruning by microglia, leading to enhanced connectivity and epilepsy (C1q KO model, Chu et al., 2010) and decreased synaptic engulfment (C3 KO or Complement Receptor 3, CR3 KO, Schafer et al., 2012). Recently, microglial CR3 activation was found to trigger long term synaptic depression (LTD), upon the combination of hypoxia and inflammatory stimuli, via NADPH oxidase. This finding suggests that microglial CR3-triggered LTD may underlie synaptic dysfunction (Zhang et al., 2014). Further investigations are required to elucidate the possible occurrence of such mechanisms during early brain development.

Progranulin (PGRN) is a protein encoded by the progranulin gene (GRN), and it is implicated in the regulation of phagocytosis and the release of pro-inflammatory cytokines in microglia and macrophages (Yin et al., 2010; Kao et al., 2011; Martens et al., 2012). GRN is associated with frontotemporal lobar degeneration, and microglia lacking GRN are shown to have an aberrant expression profile at 18 but not at 4 months of age (Lui et al., 2016). However, the same study showed that primary microglia isolated from neonatal GRN KO mice expressed more abundant levels of $\mathrm{C} 1 \mathrm{q}$ and $\mathrm{C} 3$ complement 
molecules, described to mediate synaptic pruning (see above). In vitro systems assessing the functional implication of GRN $\mathrm{KO}$ in neonatal microglia, based on primary neuronal-microglia co-culture, revealed a significant increase in synaptic pruning, and provided evidence for Clqa-tagged synaptic puncta within microglial phagocytic structures (Lui et al., 2016). These findings indicate that an aberrant complement expression by microglia, combined with an enhanced phagocytosis, is detrimental for the synaptic function.

ATG7 (autophagy related gene 7) is an E1-like activating enzyme required for cytoplasm - vacuole transport, and is essential for autophagy. Kim et al. (2016) recently showed that microglial autophagy is involved in synaptic refinement. Microglia lacking Atg7 displayed impaired degradation of synaptosomes in vitro. Deletion of Atg7 from myeloid cell-specific lysozyme M-Cre mice resulted in increased dendritic spines and synaptic markers, and was associated with long-lasting deficits in sociability, with no changes in social recognition. In addition, increased repetitive behaviors were observed in mice lacking microglial Atg7, indicating that deficient microglial function in the developing brain might lead to ASD-like behaviors (Kim et al., 2016).

Overall these findings, based on selective manipulation of microglia, indicate that genes regulating microglial functions can have a critical impact on synaptic refinement and might be involved in neurodevelopmental disorders.

\section{CONCLUSIONS}

There is substantial evidence that microglia are important cellular players during early brain maturation. Microglial activity can be modulated by a variety of environmental and genetic factors. Alterations of microglial function induced during development by agents such as stress and infections have been extensively associated with defective synaptic maturation and impairment in brain connectivity. The release of proinflammatory, neurotoxic cytokines in response to these factors has been for long time considered the most important microglialmediated mechanism leading to synaptic defects. In addition to this gain-of-toxicity, the recent literature reviewed here indicates that early microglia perturbation also induces a loss-of-function effect. In fact, many of the synaptic defects reported upon microglial depletion could be phenocopied in mouse models where the physiological activity of microglia is heavily altered. Pont-Lezica et al. (2014) showed that three different models of altered microglial activity (genetic depletion in PU.1KO mice, loss-of-function in the DAP12KO mouse line, and maternal inflammation by prenatal LPS injection) all resulted in a comparable defect of the corpus callosum development.

Consistently, Squarzoni et al. (2014) found that perturbing microglial activity using multiple mouse models, including celldepletion approaches and Cx3cr1KO, CR3KO, and DAP12KO mice led to similar defects in the outgrowth of dopaminergic axons in the forebrain and in the laminar positioning of subsets of neocortical interneurons.
These findings indicate that perturbations of microglial activity during development interfere with physiological crosstalk between microglia and synapses. One could speculate that impaired synaptic pruning and reduced release of trophic factors might be the major mediators of the synaptic defects. However, the exact molecular mechanisms remain elusive and require further investigations.

The specific timing of microglial perturbation during development is a critical factor in dictating the outcome and duration of the effects on synaptic functions. Indeed, the precise time of manipulation might affect microglial as well as neuronal developmental programs.

Microglial and macrophagic development follows a stepwise program orchestrated by the activity of specific transcription factors, which dictate discrete transcriptional phases (Hagemeyer et al., 2016; Matcovitch-Natan et al., 2016). Recent data from mouse studies suggest that this partitioning consists primarily into three major stages: early microglia until E14, pre-microglia from E14 to a few weeks after birth, and adult microglia from a few weeks after birth onward (MatcovitchNatan et al., 2016). Coordinated transcriptional events control the transitions through such microglial developmental stages and are probably due to changes in the microenvironment of the CNS. Timed perturbations of this tight shift regulation lead to altered expression patterns, thus affecting key microglial functions.

Neuronal maturation is also strictly dependent on the developmental stage. Neural circuits are refined by experience during specific time windows, defined as critical periods, early in post-natal life (Hensch, 2004). In addition, the timing of neuronal and microglial maturation is sexually dimorphic (Lenz and McCarthy, 2015; Hanamsagar and Bilbo, 2016). It could be speculated that the lack of microglial function might result in different outcome according to the sex and to the developmental stage, in which the manipulation occurs. Further studies are warranted to elucidate the effects of timing and sex on microglial sculpting of synapses.

In summary, environmental challenges as well as manipulations of microglial genes have been shown to perturb microglial activity, and to affect synapses (see Tables 2, 3). Both loss of physiological function and gain-of-toxicity in microglia, when occurring during development, can cause profound alterations in brain wiring. Abnormal synaptic pruning (insufficient or exaggerated) as well as reduced release of trophic factors (such as BDNF and IGF1) can induce aberrant or dysfunctional circuit formation. On the other hand, the release of pro-inflammatory cytokines such as IL-18 and TNF $\alpha$ can directly modulate synaptic activity, by up-regulating voltageactivated $\mathrm{Na}^{+}$currents, thus increasing neuronal excitability. Such alterations occurring in early-life have been shown to have long-lasting effects on brain function, with deficits in behavior and cognition emerging in juvenile age and adulthood (Figure 1).

Overall, there is substantial evidence that microglial dysfunction in early development leads to defective synaptic maturation and activity. Synaptic defects are a common feature shared by several neurodevelopmental and psychiatric 
disorders, such as ASD and schizophrenia. Thus, alterations in the physiological activity of microglia might be implicated in the pathogenesis of such diseases. A better understanding of the underlying molecular mechanisms might yield to the identification of novel pharmacological targets for therapeutic interventions.

\section{AUTHOR CONTRIBUTIONS}

All authors listed, have made substantial, direct and intellectual contribution to the work, and approved it for publication.

\section{REFERENCES}

Agid, O., Shapira, B., Zislin, J., Ritsner, M., Hanin, B., Murad, H., et al. (1999). Environment and vulnerability to major psychiatric illness: a case control study of early parental loss in major depression, bipolar disorder and schizophrenia. Mol. Psychiatry 4, 163-172.

Ajdacic-Gross, V., Aleksandrowicz, A., Rodgers, S., Mutsch, M., Tesic, A., Muller, M., et al. (2016). Infectious, atopic and inflammatory diseases, childhood adversities and familial aggregation are independently associated with the risk for mental disorders: results from a large Swiss epidemiological study. World J. Psychiatry 6, 419-430. doi: 10.5498/wjp.v6.i4.419

Antonietta Ajmone-Cat, M., Lavinia Salvatori, M., De Simone, R., Mancini, M., Biagioni, S., Bernardo, A., et al. (2012). Docosahexaenoic acid modulates inflammatory and antineurogenic functions of activated microglial cells. J. Neurosci. Res. 90, 575-587. doi: 10.1002/jnr.22783

Aoki, N., Kimura, S., Takiyama, Y., Atsuta, Y., Abe, A., Sato, K., et al. (2000). The role of the DAP12 signal in mouse myeloid differentiation. J. Immunol. 165, 3790-3796.

Arnoux, I., and Audinat, E. (2015). Fractalkine signaling and microglia functions in the developing brain. Neural Plast. 2015:689404. doi: 10.1155/2015/689404

Atladottir, H. O., Thorsen, P., Ostergaard, L., Schendel, D. E., Lemcke, S., Abdallah, M., et al. (2010). Maternal infection requiring hospitalization during pregnancy and autism spectrum disorders. J. Autism Dev. Disord. 40, 1423-1430. doi: 10.1007/s10803-010-1006-y

Baufeld, C., Osterloh, A., Prokop, S., Miller, K. R., and Heppner, F. L. (2016). Highfat diet-induced brain region-specific phenotypic spectrum of CNS resident microglia. Acta Neuropathol. 132, 361-375. doi: 10.1007/s00401-016-1595-4

Bessis, A., Bechade, C., Bernard, D., and Roumier, A. (2007). Microglial control of neuronal death and synaptic properties. Glia 55, 233-238. doi: 10.1002/glia. 20459

Bilbo, S. D., Biedenkapp, J. C., Der-Avakian, A., Watkins, L. R., Rudy, J. W., and Maier, S. F. (2005). Neonatal infection-induced memory impairment after lipopolysaccharide in adulthood is prevented via caspase-1 inhibition. J. Neurosci. 25, 8000-8009. doi: 10.1523/JNEUROSCI.1748-05.2005

Bilbo, S. D., Rudy, J. W., Watkins, L. R., and Maier, S. F. (2006). A behavioural characterization of neonatal infection-facilitated memory impairment in adult rats. Behav. Brain Res. 169, 39-47. doi: 10.1016/j.bbr.2005.12.002

Bilbo, S. D., and Schwarz, J. M. (2009). Early-life programming of later-life brain and behavior: a critical role for the immune system. Front. Behav. Neurosci. 3:14. doi: 10.3389/neuro.08.014.2009

Bilbo, S. D., and Schwarz, J. M. (2012). The immune system and developmental programming of brain and behavior. Front. Neuroendocrinol. 33:267-286. doi: 10.1016/j.yfrne.2012.08.006

Blinzinger, K., and Kreutzberg, G. (1968). Displacement of synaptic terminals from regenerating motoneurons by microglial cells. Z. Zellforsch. Mikrosk. Anat. 85, $145-157$.

Boksa, P. (2010). Effects of prenatal infection on brain development and behavior: a review of findings from animal models. Brain Behav. Immun. 24, 881-897. doi: 10.1016/j.bbi.2010.03.005

Bolton, J. L., Auten, R. L., and Bilbo, S. D. (2014). Prenatal air pollution exposure induces sexually dimorphic fetal programming of metabolic and

\section{FUNDING}

The authors were supported by the Synapsis Foundation Alzheimer's Research Switzerland ARS.

\section{ACKNOWLEDGMENTS}

The authors would like to thank Dr. Juliet Richetto for her valuable comments and suggestions to improve the quality of the manuscript. Sincere thanks to Dr. Abi Herrmann for editorial help.

neuroinflammatory outcomes in adult offspring. Brain Behav. Immun. 37, 30-44. doi: 10.1016/j.bbi.2013.10.029

Bolton, J. L., and Bilbo, S. D. (2014). Developmental programming of brain and behavior by perinatal diet: focus on inflammatory mechanisms. Dialogues Clin. Neurosci. 16, 307-320.

Bolton, J. L., Smith, S. H., Huff, N. C., Gilmour, M. I., Foster, W. M., Auten, R. L., et al. (2012). Prenatal air pollution exposure induces neuroinflammation and predisposes offspring to weight gain in adulthood in a sex-specific manner. FASEB J. 26, 4743-4754. doi: 10.1096/fj.12-210989

Brown, A. S. (2012). Epidemiologic studies of exposure to prenatal infection and risk of schizophrenia and autism. Dev. Neurobiol. 72, 1272-1276. doi: 10.1002/ dneu. 22024

Brown, A. S., Begg, M. D., Gravenstein, S., Schaefer, C. A., Wyatt, R. J., Bresnahan, M., et al. (2004). Serologic evidence of prenatal influenza in the etiology of schizophrenia. Arch. Gen. Psychiatry 61, 774-780. doi: 10.1001/ archpsyc.61.8.774

Bruttger, J., Karram, K., Wortge, S., Regen, T., Marini, F., Hoppmann, N., et al. (2015). Genetic cell ablation reveals clusters of local self-renewing microglia in the mammalian central nervous system. Immunity 43, 92-106. doi: 10.1016/j. immuni.2015.06.012

Buiting, A. M., and Van Rooijen, N. (1994). Liposome mediated depletion of macrophages: an approach for fundamental studies. J. Drug Target. 2, 357-362. doi: 10.3109/10611869408996810

Butovsky, O., Jedrychowski, M. P., Moore, C. S., Cialic, R., Lanser, A. J., Gabriely, G., et al. (2014). Identification of a unique TGF-beta-dependent molecular and functional signature in microglia. Nat. Neurosci. 17, 131-143. doi: 10.1038/nn.3599

Caetano, L., Pinheiro, H., Patricio, P., Mateus-Pinheiro, A., Alves, N. D., Coimbra, B., et al. (2016). Adenosine A2A receptor regulation of microglia morphological remodeling-gender bias in physiology and in a model of chronic anxiety. Mol. Psychiatry doi: 10.1038/mp.2016.173 [Epub ahead of print].

Campos, A. C., Rocha, N. P., Nicoli, J. R., Vieira, L. Q., Teixeira, M. M., and Teixeira, A. L. (2016). Absence of gut microbiota influences lipopolysaccharideinduced behavioral changes in mice. Behav. Brain Res. 312, 186-194. doi: 10.1016/j.bbr.2016.06.027

Casano, A. M., and Peri, F. (2015). Microglia: multitasking specialists of the brain. Dev. Cell 32, 469-477. doi: 10.1016/j.devcel.2015.01.018

Chang, P. K., Khatchadourian, A., McKinney, R. A., and Maysinger, D. (2015). Docosahexaenoic acid (DHA): a modulator of microglia activity and dendritic spine morphology. J. Neuroinflammation 12:34. doi: 10.1186/s12974-0150244-5

Chen, S., Zhang, H., Pu, H., Wang, G., Li, W., Leak, R. K., et al. (2014). n-3 PUFA supplementation benefits microglial responses to myelin pathology. Sci. Rep. 4:7458. doi: 10.1038/srep07458

Chen, S. K., Tvrdik, P., Peden, E., Cho, S., Wu, S., Spangrude, G., et al. (2010). Hematopoietic origin of pathological grooming in Hoxb8 mutant mice. Cell 141, 775-785. doi: 10.1016/j.cell.2010.03.055

Chu, Y., Jin, X., Parada, I., Pesic, A., Stevens, B., Barres, B., et al. (2010). Enhanced synaptic connectivity and epilepsy in C1q knockout mice. Proc. Natl. Acad. Sci. U.S.A. 107, 7975-7980. doi: 10.1073/pnas.0913449107 
Clausen, B. E., Burkhardt, C., Reith, W., Renkawitz, R., and Forster, I. (1999). Conditional gene targeting in macrophages and granulocytes using LysMcre mice. Transgenic Res. 8, 265-277.

Coull, J. A., Beggs, S., Boudreau, D., Boivin, D., Tsuda, M., Inoue, K., et al. (2005). BDNF from microglia causes the shift in neuronal anion gradient underlying neuropathic pain. Nature 438, 1017-1021. doi: 10.1038/nature04223

Cunningham, C. L., Martinez-Cerdeno, V., and Noctor, S. C. (2013). Microglia regulate the number of neural precursor cells in the developing cerebral cortex. J. Neurosci. 33, 4216-4233. doi: 10.1523/JNEUROSCI.3441-12.2013

Dai, X. M., Ryan, G. R., Hapel, A. J., Dominguez, M. G., Russell, R. G., Kapp, S., et al. (2002). Targeted disruption of the mouse colony-stimulating factor 1 receptor gene results in osteopetrosis, mononuclear phagocyte deficiency, increased primitive progenitor cell frequencies, and reproductive defects. Blood 99, 111-120.

Davalos, D., Grutzendler, J., Yang, G., Kim, J. V., Zuo, Y., Jung, S., et al. (2005). ATP mediates rapid microglial response to local brain injury in vivo. Nat. Neurosci. 8, 752-758. doi: 10.1038/nn1472

de Baumont, A., Maschietto, M., Lima, L., Carraro, D. M., Olivieri, E. H., Fiorini, A., et al. (2015). Innate immune response is differentially dysregulated between bipolar disease and schizophrenia. Schizophr. Res. 161, 215-221. doi: 10.1016/j.schres.2014.10.055

De Smedt-Peyrusse, V., Sargueil, F., Moranis, A., Harizi, H., Mongrand, S., and Laye, S. (2008). Docosahexaenoic acid prevents lipopolysaccharide-induced cytokine production in microglial cells by inhibiting lipopolysaccharide receptor presentation but not its membrane subdomain localization. J. Neurochem. 105, 296-307. doi: 10.1111/j.1471-4159.2007.05129.x

Delpech, J. C., Wei, L., Hao, J., Yu, X., Madore, C., Butovsky, O., et al. (2016). Early life stress perturbs the maturation of microglia in the developing hippocampus. Brain Behav. Immun. 57, 79-93. doi: 10.1016/j.bbi.2016.06.006

Derecki, N. C., Cronk, J. C., Lu, Z., Xu, E., Abbott, S. B., Guyenet, P. G., et al. (2012). Wild-type microglia arrest pathology in a mouse model of Rett syndrome. Nature 484, 105-109. doi: 10.1038/nature10907

Di Marco, B., Bonaccorso, C. M., Aloisi, E., D’Antoni, S., and Catania, M. V. (2016). Neuro-inflammatory mechanisms in developmental disorders associated with intellectual disability and autism spectrum disorder: a neuro- immune perspective. CNS Neurol. Disord. Drug Targets 15, 448-463.

Dissing-Olesen, L., LeDue, J. M., Rungta, R. L., Hefendehl, J. K., Choi, H. B., and MacVicar, B. A. (2014). Activation of neuronal NMDA receptors triggers transient ATP-mediated microglial process outgrowth. J. Neurosci. 34, 10511-10527. doi: 10.1523/JNEUROSCI.0405-14.2014

Diz-Chaves, Y., Astiz, M., Bellini, M. J., and Garcia-Segura, L. M. (2013). Prenatal stress increases the expression of proinflammatory cytokines and exacerbates the inflammatory response to LPS in the hippocampal formation of adult male mice. Brain Behav. Immun. 28, 196-206. doi: 10.1016/j.bbi.2012. 11.013

Diz-Chaves, Y., Pernia, O., Carrero, P., and Garcia-Segura, L. M. (2012). Prenatal stress causes alterations in the morphology of microglia and the inflammatory response of the hippocampus of adult female mice. J. Neuroinflammation 9:71. doi: 10.1186/1742-2094-9-71

Drozdowicz, L. B., and Bostwick, J. M. (2014). Psychiatric adverse effects of pediatric corticosteroid use. Mayo Clin. Proc. 89, 817-834. doi: 10.1016/j. mayocp.2014.01.010

Elkabes, S., DiCicco-Bloom, E. M., and Black, I. B. (1996). Brain microglia/macrophages express neurotrophins that selectively regulate microglial proliferation and function. J. Neurosci. 16, 2508-2521.

Elkabes, S., Peng, L., and Black, I. B. (1998). Lipopolysaccharide differentially regulates microglial trk receptor and neurotrophin expression. J. Neurosci. Res 54, 117-122. doi: 10.1002/(SICI)1097-4547(19981001)54:1<117::AIDJNR12<3.0.CO;2-4

Elmore, M. R., Najafi, A. R., Koike, M. A., Dagher, N. N., Spangenberg, E. E., Rice, R. A., et al. (2014). Colony-stimulating factor 1 receptor signaling is necessary for microglia viability, unmasking a microglia progenitor cell in the adult brain. Neuron 82, 380-397. doi: 10.1016/j.neuron.2014.02.040

Erblich, B., Zhu, L., Etgen, A. M., Dobrenis, K., and Pollard, J. W. (2011). Absence of colony stimulation factor-1 receptor results in loss of microglia, disrupted brain development and olfactory deficits. PLOS ONE 6:e26317. doi: 10.1371/ journal.pone. 0026317
Erny, D., Hrabe de Angelis, A. L., Jaitin, D., Wieghofer, P., Staszewski, O., David, E., et al. (2015). Host microbiota constantly control maturation and function of microglia in the CNS. Nat. Neurosci. 18, 965-977. doi: 10.1038/nn.4030

Erny, D., Hrabe de Angelis, A. L., and Prinz, M. (2017). Communicating systems in the body: how microbiota and microglia cooperate. Immunology 150, 7-15. doi: 10.1111/imm.12645

Estes, M. L., and McAllister, A. K. (2016). Maternal immune activation: Implications for neuropsychiatric disorders. Science 353, 772-777. doi: 10.1126/ science.aag3194

Favrais, G., van de Looij, Y., Fleiss, B., Ramanantsoa, N., Bonnin, P., StoltenburgDidinger, G., et al. (2011). Systemic inflammation disrupts the developmental program of white matter. Ann. Neurol. 70, 550-565. doi: 10.1002/ana.22489

Fernandez de Cossio, L., Guzman, A., van der Veldt, S., and Luheshi, G. N. (2016). Prenatal infection leads to ASD-like behavior and altered synaptic pruning in the mouse offspring. Brain Behav. Immun. doi: 10.1016/j.bbi.2016.09.028 [Epub ahead of print].

Ferron, M., and Vacher, J. (2005). Targeted expression of Cre recombinase in macrophages and osteoclasts in transgenic mice. Genesis 41, 138-145. doi: 10.1002/gene.20108

Fontainhas, A. M., Wang, M., Liang, K. J., Chen, S., Mettu, P., Damani, M., et al. (2011). Microglial morphology and dynamic behavior is regulated by ionotropic glutamatergic and GABAergic neurotransmission. PLOS ONE 6:e15973. doi: 10.1371/journal.pone.0015973

Forrest, C. M., Khalil, O. S., Pisar, M., Smith, R. A., Darlington, L. G., and Stone, T. W. (2012). Prenatal activation of Toll-like receptors-3 by administration of the viral mimetic poly(I:C) changes synaptic proteins, N-methyl-D-aspartate receptors and neurogenesis markers in offspring. Mol. Brain 5:22. doi: 10.1186/ 1756-6606-5-22

Fuertig, R., Azzinnari, D., Bergamini, G., Cathomas, F., Sigrist, H., Seifritz, E., et al. (2016). Mouse chronic social stress increases blood and brain kynurenine pathway activity and fear behaviour: Both effects are reversed by inhibition of indoleamine 2,3-dioxygenase. Brain Behav. Immun. 54, 59-72. doi: 10.1016/j. bbi.2015.12.020

Garay, P. A., Hsiao, E. Y., Patterson, P. H., and McAllister, A. K. (2013). Maternal immune activation causes age- and region-specific changes in brain cytokines in offspring throughout development. Brain Behav. Immun. 31, 54-68. doi: 10.1016/j.bbi.2012.07.008

Gilmore, J. H., Jarskog, L. F., and Vadlamudi, S. (2005). Maternal poly I:C exposure during pregnancy regulates TNF alpha, BDNF, and NGF expression in neonatal brain and the maternal-fetal unit of the rat. J. Neuroimmunol. 159, 106-112. doi: 10.1016/j.jneuroim.2004.10.008

Ginhoux, F., Greter, M., Leboeuf, M., Nandi, S., See, P., Gokhan, S., et al. (2010). Fate mapping analysis reveals that adult microglia derive from primitive macrophages. Science 330, 841-845. doi: 10.1126/science.1194637

Giovanoli, S., Engler, H., Engler, A., Richetto, J., Feldon, J., Riva, M. A., et al. (2016a). Preventive effects of minocycline in a neurodevelopmental two-hit model with relevance to schizophrenia. Transl. Psychiatry 6, e772. doi: 10.1038/ tp. 2016.38

Giovanoli, S., Weber-Stadlbauer, U., Schedlowski, M., Meyer, U., and Engler, H. (2016b). Prenatal immune activation causes hippocampal synaptic deficits in the absence of overt microglia anomalies. Brain Behav. Immun. 55, 25-38. doi: 10.1016/j.bbi.2015.09.015

Giugliano, D., Ceriello, A., and Esposito, K. (2006). The effects of diet on inflammation: emphasis on the metabolic syndrome. J. Am. Coll. Cardiol. 48, 677-685. doi: 10.1016/j.jacc.2006.03.052

Goldmann, T., Wieghofer, P., Jordao, M. J., Prutek, F., Hagemeyer, N., Frenzel, K., et al. (2016). Origin, fate and dynamics of macrophages at central nervous system interfaces. Nat. Immunol. 17, 797-805. doi: 10.1038/ni.3423

Gomez-Gonzalez, B., and Escobar, A. (2010). Prenatal stress alters microglial development and distribution in postnatal rat brain. Acta Neuropathol. 119, 303-315. doi: 10.1007/s00401-009-0590-4

Guillemot-Legris, O., Masquelier, J., Everard, A., Cani, P. D., Alhouayek, M., and Muccioli, G. G. (2016). High-fat diet feeding differentially affects the development of inflammation in the central nervous system. J. Neuroinflammation 13:206. doi: 10.1186/s12974-016-0666-8

Gupta, S., Ellis, S. E., Ashar, F. N., Moes, A., Bader, J. S., Zhan, J., et al. (2014). Transcriptome analysis reveals dysregulation of innate immune response genes 
and neuronal activity-dependent genes in autism. Nat. Commun. 5, 5748. doi: $10.1038 /$ ncomms6748

Gzielo, K., Kielbinski, M., Ploszaj, J., Janeczko, K., Gazdzinski, S. P., and Setkowicz, Z. (2016). Long-term consumption of high-fat diet in rats: effects on microglial and astrocytic morphology and neuronal nitric oxide synthase expression. Cell Mol. Neurobiol. doi: 10.1007/s10571-016-0417-5 [Epub ahead of print].

Hagemeyer, N., Kierdorf, K., Frenzel, K., Xue, J., Ringelhan, M., Abdullah, Z., et al. (2016). Transcriptome-based profiling of yolk sac-derived macrophages reveals a role for Irf8 in macrophage maturation. EMBO J. 35, 1730-1744. doi: 10.15252/embj.201693801

Hanamsagar, R., and Bilbo, S. D. (2016). Sex differences in neurodevelopmental and neurodegenerative disorders: focus on microglial function and neuroinflammation during development. J. Steroid Biochem. Mol. Biol. 160, 127-133. doi: 10.1016/j.jsbmb.2015.09.039

Hao, S., Dey, A., Yu, X., and Stranahan, A. M. (2016). Dietary obesity reversibly induces synaptic stripping by microglia and impairs hippocampal plasticity. Brain Behav. Immun. 51, 230-239. doi: 10.1016/j.bbi.2015.08.023

Hava, G., Vered, L., Yael, M., Mordechai, H., and Mahoud, H. (2006). Alterations in behavior in adult offspring mice following maternal inflammation during pregnancy. Dev. Psychobiol. 48, 162-168. doi: 10.1002/dev.20116

Haynes, S. E., Hollopeter, G., Yang, G., Kurpius, D., Dailey, M. E., Gan, W. B., et al. (2006). The P2Y12 receptor regulates microglial activation by extracellular nucleotides. Nat. Neurosci. 9, 1512-1519. doi: 10.1038/nn1805

Hellwig, S., Brioschi, S., Dieni, S., Frings, L., Masuch, A., Blank, T., et al. (2016). Altered microglia morphology and higher resilience to stress-induced depression-like behavior in CX3CR1-deficient mice. Brain Behav. Immun. 55, 126-137. doi: 10.1016/j.bbi.2015.11.008

Hensch, T. K. (2004). Critical period regulation. Annu. Rev. Neurosci. 27, 549-579. doi: 10.1146/annurev.neuro.27.070203.144327

Heppner, F. L., Greter, M., Marino, D., Falsig, J., Raivich, G., Hovelmeyer, N., et al. (2005). Experimental autoimmune encephalomyelitis repressed by microglial paralysis. Nat. Med. 11, 146-152. doi: 10.1038/nm1177

Hilakivi-Clarke, L., Cho, E., and Onojafe, I. (1996). High-fat diet induces aggressive behavior in male mice and rats. Life Sci. 58, 1653-1660.

Hinwood, M., Morandini, J., Day, T. A., and Walker, F. R. (2012). Evidence that microglia mediate the neurobiological effects of chronic psychological stress on the medial prefrontal cortex. Cereb. Cortex 22, 1442-1454. doi: 10.1093/cercor/ bhr229

Hinwood, M., Tynan, R. J., Charnley, J. L., Beynon, S. B., Day, T. A., and Walker, F. R. (2013). Chronic stress induced remodeling of the prefrontal cortex: structural re-organization of microglia and the inhibitory effect of minocycline. Cereb. Cortex 23, 1784-1797. doi: 10.1093/cercor/bhs151

Hoeffel, G., Chen, J., Lavin, Y., Low, D., Almeida, F. F., See, P., et al. (2015). $\mathrm{C}-\mathrm{Myb}(+)$ erythro-myeloid progenitor-derived fetal monocytes give rise to adult tissue-resident macrophages. Immunity 42, 665-678. doi: 10.1016/j. immuni.2015.03.011

Hohn, A., Leibrock, J., Bailey, K., and Barde, Y. A. (1990). Identification and characterization of a novel member of the nerve growth factor/brainderived neurotrophic factor family. Nature 344, 339-341. doi: 10.1038/ 344339a0

Hopperton, K. E., Trepanier, M. O., Giuliano, V., and Bazinet, R. P. (2016). Brain omega-3 polyunsaturated fatty acids modulate microglia cell number and morphology in response to intracerebroventricular amyloidbeta 1-40 in mice. J. Neuroinflammation 13, 257. doi: 10.1186/s12974-0160721-5

Hoshiko, M., Arnoux, I., Avignone, E., Yamamoto, N., and Audinat, E. (2012). Deficiency of the microglial receptor CX3CR1 impairs postnatal functional development of thalamocortical synapses in the barrel cortex. J. Neurosci. 32, 15106-15111. doi: 10.1523/JNEUROSCI.1167-12.2012

Igelhorst, B. A., Niederkinkhaus, V., Karus, C., Lange, M. D., and Dietzel, I. D. (2015). Regulation of neuronal excitability by release of proteins from glial cells. Philos. Trans. R. Soc. Lond. B Biol. Sci. 370:20140194. doi: 10.1098/rstb.2014. 0194

Iwasaki, H., Somoza, C., Shigematsu, H., Duprez, E. A., Iwasaki-Arai, J., Mizuno, S., et al. (2005). Distinctive and indispensable roles of PU.1 in maintenance of hematopoietic stem cells and their differentiation. Blood 106, 1590-1600. doi: 10.1182/blood-2005-03-0860
Ji, K., Akgul, G., Wollmuth, L. P., and Tsirka, S. E. (2013a). Microglia actively regulate the number of functional synapses. PLOS ONE 8:e56293. doi: 10.1371/ journal.pone.0056293

Ji, K., Miyauchi, J., and Tsirka, S. E. (2013b). Microglia: an active player in the regulation of synaptic activity. Neural Plast. 2013:627325. doi: 10.1155/2013/ 627325

Jung, S., Aliberti, J., Graemmel, P., Sunshine, M. J., Kreutzberg, G. W., Sher, A., et al. (2000). Analysis of fractalkine receptor CX(3)CR1 function by targeted deletion and green fluorescent protein reporter gene insertion. Mol. Cell. Biol. 20, 4106-4114.

Kaifu, T., Nakahara, J., Inui, M., Mishima, K., Momiyama, T., Kaji, M., et al. (2003). Osteopetrosis and thalamic hypomyelinosis with synaptic degeneration in DAP12-deficient mice. J. Clin. Invest. 111, 323-332. doi: 10.1172/JCI16923

Kao, A. W., Eisenhut, R. J., Martens, L. H., Nakamura, A., Huang, A., Bagley, J. A., et al. (2011). A neurodegenerative disease mutation that accelerates the clearance of apoptotic cells. Proc. Natl. Acad. Sci. U.S.A. 108, 4441-4446. doi: 10.1073/pnas.1100650108

Kettenmann, H., Kirchhoff, F., and Verkhratsky, A. (2013). Microglia: new roles for the synaptic stripper. Neuron 77, 10-18. doi: 10.1016/j.neuron.2012.12.023

Kierdorf, K., Erny, D., Goldmann, T., Sander, V., Schulz, C., Perdiguero, E. G., et al. (2013). Microglia emerge from erythromyeloid precursors via Pu.1- and Irf8-dependent pathways. Nat. Neurosci. 16, 273-280. doi: 10.1038/nn.3318

Kim, H. J., Cho, M. H., Shim, W. H., Kim, J. K., Jeon, E. Y., Kim, D. H., et al. (2016). Deficient autophagy in microglia impairs synaptic pruning and causes social behavioral defects. Mol. Psychiatry doi: 10.1038/mp.2016.103 [Epub ahead of print].

Kinney, D. K., Munir, K. M., Crowley, D. J., and Miller, A. M. (2008). Prenatal stress and risk for autism. Neurosci. Biobehav. Rev. 32, 1519-1532. doi: 10.1016/ j.neubiorev.2008.06.004

Kirsten, T. B., Taricano, M., Maiorka, P. C., Palermo-Neto, J., and Bernardi, M. M. (2010). Prenatal lipopolysaccharide reduces social behavior in male offspring. Neuroimmunomodulation 17, 240-251. doi: 10.1159/000290040

Klapal, L., Igelhorst, B. A., and Dietzel-Meyer, I. D. (2016). Changes in neuronal excitability by activated microglia: differential $\mathrm{Na}(+)$ current upregulation in pyramid-shaped and bipolar neurons by TNF-alpha and IL-18. Front. Neurol. 7:44. doi: 10.3389/fneur.2016.00044

Knuesel, I., Chicha, L., Britschgi, M., Schobel, S. A., Bodmer, M., Hellings, J. A., et al. (2014). Maternal immune activation and abnormal brain development across CNS disorders. Nat. Rev. Neurol. 10, 643-660. doi: 10.1038/nrneurol. 2014.187

Kreisel, T., Frank, M. G., Licht, T., Reshef, R., Ben-Menachem-Zidon, O., Baratta, M. V., et al. (2014). Dynamic microglial alterations underlie stress-induced depressive-like behavior and suppressed neurogenesis. Mol. Psychiatry 19, 699-709. doi: 10.1038/mp.2013.155

Larrieu, T., Madore, C., Joffre, C., and Laye, S. (2012). Nutritional n-3 polyunsaturated fatty acids deficiency alters cannabinoid receptor signaling pathway in the brain and associated anxiety-like behavior in mice. J. Physiol. Biochem. 68, 671-681. doi: 10.1007/s13105-012-0179-6

Lenz, K. M., and McCarthy, M. M. (2015). A starring role for microglia in brain sex differences. Neuroscientist 21, 306-321. doi: 10.1177/1073858414536468

Li, Y., Du, X. F., Liu, C. S., Wen, Z. L., and Du, J. L. (2012). Reciprocal regulation between resting microglial dynamics and neuronal activity in vivo. Dev. Cell 23, 1189-1202. doi: 10.1016/j.devcel.2012.10.027

Lieblein-Boff, J. C., McKim, D. B., Shea, D. T., Wei, P., Deng, Z., Sawicki, C., et al. (2013). Neonatal E. coli infection causes neuro-behavioral deficits associated with hypomyelination and neuronal sequestration of iron. J. Neurosci. 33, 16334-16345. doi: 10.1523/JNEUROSCI.0708-13.2013

Limatola, C., and Ransohoff, R. M. (2014). Modulating neurotoxicity through CX3CL1/CX3CR1 signaling. Front. Cell Neurosci. 8:229. doi: 10.3389/fncel. 2014.00229

Ling, Z., Zhu, Y., Tong, C., Snyder, J. A., Lipton, J. W., and Carvey, P. M. (2006). Progressive dopamine neuron loss following supra-nigral lipopolysaccharide (LPS) infusion into rats exposed to LPS prenatally. Exp. Neurol. 199, 499-512. doi: 10.1016/j.expneurol.2006.01.010

Lu, B., Pang, P. T., and Woo, N. H. (2005). The yin and yang of neurotrophin action. Nat. Rev. Neurosci. 6, 603-614. doi: 10.1038/nrn1726

Lui, H., Zhang, J., Makinson, S. R., Cahill, M. K., Kelley, K. W., Huang, H. Y., et al. (2016). Progranulin deficiency promotes circuit-specific synaptic pruning 
by microglia via complement activation. Cell 165, 921-935. doi: 10.1016/j.cell. 2016.04.001

MacMillan, H. L., Fleming, J. E., Streiner, D. L., Lin, E., Boyle, M. H., Jamieson, E., et al. (2001). Childhood abuse and lifetime psychopathology in a community sample. Am. J. Psychiatry 158, 1878-1883. doi: 10.1176/appi.ajp.158.11.1878

Madore, C., Nadjar, A., Delpech, J. C., Sere, A., Aubert, A., Portal, C., et al. (2014). Nutritional n-3 PUFAs deficiency during perinatal periods alters brain innate immune system and neuronal plasticity-associated genes. Brain Behav. Immun. 41, 22-31. doi: 10.1016/j.bbi.2014.03.021

Maezawa, I., and Jin, L. W. (2010). Rett syndrome microglia damage dendrites and synapses by the elevated release of glutamate. J. Neurosci. 30, 5346-5356. doi: 10.1523/JNEUROSCI.5966-09.2010

Maggi, L., Scianni, M., Branchi, I., D’Andrea, I., Lauro, C., and Limatola, C. (2011). CX(3)CR1 deficiency alters hippocampal-dependent plasticity phenomena blunting the effects of enriched environment. Front. Cell Neurosci. 5:22. doi: $10.3389 /$ fncel.2011.00022

Majewska, A., and Sur, M. (2003). Motility of dendritic spines in visual cortex in vivo: changes during the critical period and effects of visual deprivation. Proc. Natl. Acad. Sci. U.S.A. 100, 16024-16029. doi: 10.1073/pnas.2636949100

Marques, A. H., Bjorke-Monsen, A. L., Teixeira, A. L., and Silverman, M. N. (2015). Maternal stress, nutrition and physical activity: impact on immune function, CNS development and psychopathology. Brain Res. 1617, 28-46. doi: 10.1016/ j.brainres.2014.10.051

Marques, A. H., O’Connor, T. G., Roth, C., Susser, E., and Bjorke-Monsen, A. L. (2013). The influence of maternal prenatal and early childhood nutrition and maternal prenatal stress on offspring immune system development and neurodevelopmental disorders. Front. Neurosci. 7:120. doi: 10.3389/fnins.2013. 00120

Martens, L. H., Zhang, J., Barmada, S. J., Zhou, P., Kamiya, S., Sun, B., et al. (2012). Progranulin deficiency promotes neuroinflammation and neuron loss following toxin-induced injury. J. Clin. Invest. 122, 3955-3959. doi: 10.1172/JCI63113

Matcovitch-Natan, O., Winter, D. R., Giladi, A., Vargas Aguilar, S., Spinrad, A., Sarrazin, S., et al. (2016). Microglia development follows a stepwise program to regulate brain homeostasis. Science 353:aad8670. doi: 10.1126/science.aad8670

Mattei, D., Djodari-Irani, A., Hadar, R., Pelz, A., de Cossio, L. F., Goetz, T., et al. (2014). Minocycline rescues decrease in neurogenesis, increase in microglia cytokines and deficits in sensorimotor gating in an animal model of schizophrenia. Brain Behav. Immun. 38, 175-184. doi: 10.1016/j.bbi.2014. 01.019

Mazaheri, F., Breus, O., Durdu, S., Haas, P., Wittbrodt, J., Gilmour, D., et al. (2014). Distinct roles for BAI1 and TIM-4 in the engulfment of dying neurons by microglia. Nat. Commun. 5:4046. doi: 10.1038/ncomms5046

Merle, N. S., Church, S. E., Fremeaux-Bacchi, V., and Roumenina, L. T. (2015). Complement system part I - molecular mechanisms of activation and regulation. Front. Immunol. 6:262. doi: 10.3389/fimmu.2015.00262

Merlot, E., Couret, D., and Otten, W. (2008). Prenatal stress, fetal imprinting and immunity. Brain Behav. Immun. 22, 42-51. doi: 10.1016/j.bbi.2007.05.007

Meyer, U. (2014). Prenatal poly(i:C) exposure and other developmental immune activation models in rodent systems. Biol. Psychiatry 75, 307-315. doi: 10.1016/ j.biopsych.2013.07.011

Meyer, U., Feldon, J., Schedlowski, M., and Yee, B. K. (2005). Towards an immunoprecipitated neurodevelopmental animal model of schizophrenia. Neurosci. Biobehav. Rev. 29, 913-947. doi: 10.1016/j.neubiorev.2004.10.012

Meyer, U., Nyffeler, M., Engler, A., Urwyler, A., Schedlowski, M., Knuesel, I., et al. (2006). The time of prenatal immune challenge determines the specificity of inflammation-mediated brain and behavioral pathology. J. Neurosci. 26, 4752-4762. doi: 10.1523/JNEUROSCI.0099-06.2006

Milior, G., Lecours, C., Samson, L., Bisht, K., Poggini, S., Pagani, F., et al. (2016), Fractalkine receptor deficiency impairs microglial and neuronal responsiveness to chronic stress. Brain Behav. Immun. 55, 114-125. doi: 10.1016/j.bbi.2015. 07.024

Mintz, M., Ruedi-Bettschen, D., Feldon, J., and Pryce, C. R. (2005). Early social and physical deprivation leads to reduced social motivation in adulthood in Wistar rats. Behav. Brain Res. 156, 311-320. doi: 10.1016/j.bbr.2004.08.017

Miyamoto, A., Wake, H., Ishikawa, A. W., Eto, K., Shibata, K., Murakoshi, H., et al. (2016). Microglia contact induces synapse formation in developing somatosensory cortex. Nat. Commun. 7:12540. doi: 10.1038/ncomms 12540
Mizutani, M., Pino, P. A., Saederup, N., Charo, I. F., Ransohoff, R. M., and Cardona, A. E. (2012). The fractalkine receptor but not CCR2 is present on microglia from embryonic development throughout adulthood. J. Immunol. 188, 29-36. doi: 10.4049/jimmunol.1100421

Moranis, A., Delpech, J. C., De Smedt-Peyrusse, V., Aubert, A., Guesnet, P., Lavialle, M., et al. (2012). Long term adequate n-3 polyunsaturated fatty acid diet protects from depressive-like behavior but not from working memory disruption and brain cytokine expression in aged mice. Brain Behav. Immun. 26, 721-731. doi: 10.1016/j.bbi.2011.11.001

Nelson, L. H., and Lenz, K. M. (2017). Microglia depletion in early life programs persistent changes in social, mood-related, and locomotor behavior in male and female rats. Behav. Brain Res. 316, 279-293. doi: 10.1016/j.bbr.2016.09.006

Nimmerjahn, A., Kirchhoff, F., and Helmchen, F. (2005). Resting microglial cells are highly dynamic surveillants of brain parenchyma in vivo. Science 308, 1314-1318. doi: 10.1126/science.1110647

Nishi, M., Horii-Hayashi, N., and Sasagawa, T. (2014). Effects of early life adverse experiences on the brain: implications from maternal separation models in rodents. Front. Neurosci. 8:166. doi: 10.3389/fnins.2014.00166

Oh-Nishi, A., Obayashi, S., Sugihara, I., Minamimoto, T., and Suhara, T. (2010). Maternal immune activation by polyriboinosinic-polyribocytidilic acid injection produces synaptic dysfunction but not neuronal loss in the hippocampus of juvenile rat offspring. Brain Res. 1363, 170-179. doi: 10.1016/j. brainres.2010.09.054

Ortega, R. M., Requejo, A. M., Andres, P., Lopez-Sobaler, A. M., Quintas, M. E., Redondo, M. R., et al. (1997). Dietary intake and cognitive function in a group of elderly people. Am. J. Clin. Nutr. 66, 803-809.

Pagani, F., Paolicelli, R. C., Murana, E., Cortese, B., Di Angelantonio, S., Zurolo, E., et al. (2015). Defective microglial development in the hippocampus of Cx3cr1 deficient mice. Front. Cell Neurosci. 9:111. doi: 10.3389/fncel.2015.00111

Pang, Y., Dai, X., Roller, A., Carter, K., Paul, I., Bhatt, A. J., et al. (2016). Early postnatal lipopolysaccharide exposure leads to enhanced neurogenesis and impaired communicative functions in rats. PLOS ONE 11:e0164403. doi: 10.1371/journal.pone.0164403

Paolicelli, R. C., Bisht, K., and Tremblay, M. E. (2014). Fractalkine regulation of microglial physiology and consequences on the brain and behavior. Front. Cell Neurosci. 8:129. doi: 10.3389/fncel.2014.00129

Paolicelli, R. C., Bolasco, G., Pagani, F., Maggi, L., Scianni, M., Panzanelli, P., et al. (2011). Synaptic pruning by microglia is necessary for normal brain development. Science 333, 1456-1458. doi: 10.1126/science.1202529

Paolicelli, R. C., and Gross, C. T. (2011). Microglia in development: linking brain wiring to brain environment. Neuron Glia Biol. 7, 77-83. doi: 10.1017/ S1740925X12000105

Park, H., and Poo, M. M. (2013). Neurotrophin regulation of neural circuit development and function. Nat. Rev. Neurosci. 14, 7-23. doi: 10.1038/nrn3379

Parkhurst, C. N., Yang, G., Ninan, I., Savas, J. N., Yates, J. R. III, Lafaille, J. J., et al. (2013). Microglia promote learning-dependent synapse formation through brain-derived neurotrophic factor. Cell 155, 1596-1609. doi: 10.1016/j.cell.2013. 11.030

Pedersen, C. B., and Mortensen, P. B. (2001). Evidence of a dose-response relationship between urbanicity during upbringing and schizophrenia risk. Arch. Gen. Psychiatry 58, 1039-1046.

Pistell, P. J., Morrison, C. D., Gupta, S., Knight, A. G., Keller, J. N., Ingram, D. K., et al. (2010). Cognitive impairment following high fat diet consumption is associated with brain inflammation. J. Neuroimmunol. 219, 25-32. doi: 10.1016/ j.jneuroim.2009.11.010

Pont-Lezica, L., Beumer, W., Colasse, S., Drexhage, H., Versnel, M., and Bessis, A. (2014). Microglia shape corpus callosum axon tract fasciculation: functional impact of prenatal inflammation. Eur. J. Neurosci. 39, 1551-1557. doi: 10.1111/ ejn. 12508

Pratt, L., Ni, L., Ponzio, N. M., and Jonakait, G. M. (2013). Maternal inflammation promotes fetal microglial activation and increased cholinergic expression in the fetal basal forebrain: role of interleukin-6. Pediatr. Res. 74, 393-401. doi: 10.1038/pr.2013.126

Puntener, U., Booth, S. G., Perry, V. H., and Teeling, J. L. (2012). Long-term impact of systemic bacterial infection on the cerebral vasculature and microglia. J Neuroinflammation 9:146. doi: 10.1186/1742-2094-9-146

Ragozzino, D., Di Angelantonio, S., Trettel, F., Bertollini, C., Maggi, L., Gross, C., et al. (2006). Chemokine fractalkine/CX3CL1 negatively modulates 
active glutamatergic synapses in rat hippocampal neurons. J. Neurosci. 26, 10488-10498. doi: 10.1523/JNEUROSCI.3192-06.2006

Richetto, J., Chesters, R., Cattaneo, A., Labouesse, M. A., Gutierrez, A. M., Wood, T. C., et al. (2016). Genome-wide transcriptional profiling and structural magnetic resonance imaging in the maternal immune activation model of neurodevelopmental disorders. Cereb. Cortex doi: 10.1093/cercor/bhw320 [Epub ahead of print].

Rogers, J. T., Morganti, J. M., Bachstetter, A. D., Hudson, C. E., Peters, M. M., Grimmig, B. A., et al. (2011). CX3CR1 deficiency leads to impairment of hippocampal cognitive function and synaptic plasticity. J. Neurosci. 31, 16241-16250. doi: 10.1523/JNEUROSCI.3667-11.2011

Roque, A., Ochoa-Zarzosa, A., and Torner, L. (2016). Maternal separation activates microglial cells and induces an inflammatory response in the hippocampus of male rat pups, independently of hypothalamic and peripheral cytokine levels. Brain Behav. Immun. 55, 39-48. doi: 10.1016/j.bbi.2015.09.017

Roumier, A., Bechade, C., Poncer, J. C., Smalla, K. H., Tomasello, E., Vivier, E., et al. (2004). Impaired synaptic function in the microglial KARAP/DAP12-deficient mouse. J. Neurosci. 24, 11421-11428. doi: 10.1523/JNEUROSCI.2251-04.2004

Roumier, A., Pascual, O., Bechade, C., Wakselman, S., Poncer, J. C., Real, E., et al. (2008). Prenatal activation of microglia induces delayed impairment of glutamatergic synaptic function. PLoS ONE 3:e2595. doi: 10.1371/journal.pone. 0002595

Ruedi-Bettschen, D., Pedersen, E. M., Feldon, J., and Pryce, C. R. (2005). Early deprivation under specific conditions leads to reduced interest in reward in adulthood in Wistar rats. Behav. Brain Res. 156, 297-310. doi: 10.1016/j.bbr. 2004.06.001

Sasaki, Y., Hoshi, M., Akazawa, C., Nakamura, Y., Tsuzuki, H., Inoue, K., et al. (2003). Selective expression of Gi/o-coupled ATP receptor P2Y12 in microglia in rat brain. Glia 44, 242-250. doi: 10.1002/glia.10293

Schafer, D. P., Lehrman, E. K., Kautzman, A. G., Koyama, R., Mardinly, A. R., Yamasaki, R., et al. (2012). Microglia sculpt postnatal neural circuits in an activity and complement-dependent manner. Neuron 74, 691-705. doi: 10.1016/j.neuron.2012.03.026

Schafer, D. P., Lehrman, E. K., and Stevens, B. (2013). The "quad-partite" synapse: microglia-synapse interactions in the developing and mature CNS. Glia 61, 24-36. doi: 10.1002/glia.22389

Sekar, A., Bialas, A. R., de Rivera, H., Davis, A., Hammond, T. R., Kamitaki, N., et al. (2016). Schizophrenia risk from complex variation of complement component 4. Nature 530, 177-183. doi: 10.1038/nature 16549

Sharma, S., Zhuang, Y., and Gomez-Pinilla, F. (2012). High-fat diet transition reduces brain DHA levels associated with altered brain plasticity and behaviour. Sci. Rep. 2:431. doi: 10.1038/srep00431

Shi, L., Fatemi, S. H., Sidwell, R. W., and Patterson, P. H. (2003). Maternal influenza infection causes marked behavioral and pharmacological changes in the offspring. J. Neurosci. 23, 297-302.

Shigemoto-Mogami, Y., Hoshikawa, K., Goldman, J. E., Sekino, Y., and Sato, K. (2014). Microglia enhance neurogenesis and oligodendrogenesis in the early postnatal subventricular zone. J. Neurosci. 34, 2231-2243. doi: 10.1523/ JNEUROSCI.1619-13.2014

Sierra, A., Tremblay, M. E., and Wake, H. (2014). Never-resting microglia: physiological roles in the healthy brain and pathological implications. Front. Cell Neurosci. 8:240. doi: 10.3389/fncel.2014.00240

Sipe, G. O., Lowery, R. L., Tremblay, M. E., Kelly, E. A., Lamantia, C. E., and Majewska, A. K. (2016). Microglial P2Y12 is necessary for synaptic plasticity in mouse visual cortex. Nat. Commun. 7:10905. doi: 10.1038/ncomms10905

Slusarczyk, J., Trojan, E., Glombik, K., Budziszewska, B., Kubera, M., Lason, W., et al. (2015). Prenatal stress is a vulnerability factor for altered morphology and biological activity of microglia cells. Front. Cell Neurosci. 9:82. doi: 10.3389/ fncel.2015.00082

Smith, P. A. (2015). The tantalizing links between gut microbes and the brain. Nature 526, 312-314. doi: $10.1038 / 526312 \mathrm{a}$

Smith, P. L., Hagberg, H., Naylor, A. S., and Mallard, C. (2014). Neonatal peripheral immune challenge activates microglia and inhibits neurogenesis in the developing murine hippocampus. Dev. Neurosci. 36, 119-131. doi: 10.1159/ 000359950

Smith, S. E., Li, J., Garbett, K., Mirnics, K., and Patterson, P. H. (2007). Maternal immune activation alters fetal brain development through interleukin-6. J. Neurosci. 27, 10695-10702. doi: 10.1523/JNEUROSCI.2178-07.2007
Smolders, S., Smolders, S. M., Swinnen, N., Gartner, A., Rigo, J. M., Legendre, P., et al. (2015). Maternal immune activation evoked by polyinosinic: polycytidylic acid does not evoke microglial cell activation in the embryo. Front. Cell Neurosci. 9:301. doi: 10.3389/fncel.2015.00301

Sominsky, L., Walker, A. K., Ong, L. K., Tynan, R. J., Walker, F. R., and Hodgson, D. M. (2012). Increased microglial activation in the rat brain following neonatal exposure to a bacterial mimetic. Behav. Brain Res. 226, 351-356. doi: 10.1016/j. bbr.2011.08.038

Squarzoni, P., Oller, G., Hoeffel, G., Pont-Lezica, L., Rostaing, P., Low, D., et al. (2014). Microglia modulate wiring of the embryonic forebrain. Cell Rep. 8, 1271-1279. doi: 10.1016/j.celrep.2014.07.042

St Clair, M. C., Croudace, T., Dunn, V. J., Jones, P. B., Herbert, J., and Goodyer, I. M. (2015). Childhood adversity subtypes and depressive symptoms in early and late adolescence. Dev. Psychopathol. 27, 885-899. doi: 10.1017/S095457941400 0625

Stevens, B., Allen, N. J., Vazquez, L. E., Howell, G. R., Christopherson, K. S., Nouri, N., et al. (2007). The classical complement cascade mediates CNS synapse elimination. Cell 131, 1164-1178. doi: 10.1016/j.cell.2007.10.036

Takano, T. (2015). Role of microglia in Autism: recent advances. Dev. Neurosci. 37, 195-202. doi: 10.1159/000398791

Takase, K., Tsuneoka, Y., Oda, S., Kuroda, M., and Funato, H. (2016). High-fat diet feeding alters olfactory-, social-, and reward-related behaviors of mice independent of obesity. Obesity 24, 886-894. doi: 10.1002/oby.21441

Takatsuru, Y., Nabekura, J., Ishikawa, T., Kohsaka, S., and Koibuchi, N. (2015). Early-life stress increases the motility of microglia in adulthood. J. Physiol. Sci. 65, 187-194. doi: 10.1007/s12576-015-0361-z

Tarozzo, G., Bortolazzi, S., Crochemore, C., Chen, S. C., Lira, A. S., Abrams, J. S., et al. (2003). Fractalkine protein localization and gene expression in mouse brain. J. Neurosci. Res. 73, 81-88. doi: 10.1002/jnr.10645

Thompson, M. L., Jimenez-Andrade, J. M., Chartier, S., Tsai, J., Burton, E. A., Habets, G., et al. (2015). Targeting cells of the myeloid lineage attenuates pain and disease progression in a prostate model of bone cancer. Pain 156, 1692-1702. doi: 10.1097/j.pain.0000000000000228

Torres, L., Danver, J., Ji, K., Miyauchi, J. T., Chen, D., Anderson, M. E., et al. (2016). Dynamic microglial modulation of spatial learning and social behavior. Brain Behav. Immun. 55, 6-16. doi: 10.1016/j.bbi.2015.09.001

Trang, T., Beggs, S., and Salter, M. W. (2011). Brain-derived neurotrophic factor from microglia: a molecular substrate for neuropathic pain. Neuron Glia Biol 7, 99-108. doi: 10.1017/S1740925X12000087

Tremblay, M. E., Lowery, R. L., and Majewska, A. K. (2010). Microglial interactions with synapses are modulated by visual experience. PLoS Biol. 8:e1000527. doi: 10.1371/journal.pbio.1000527

Tremblay, M. E., Zhang, I., Bisht, K., Savage, J. C., Lecours, C., Parent, M., et al. (2016). Remodeling of lipid bodies by docosahexaenoic acid in activated microglial cells. J. Neuroinflammation 13:116. doi: 10.1186/s12974-0160580-0

Turrin, N. P., Gayle, D., Ilyin, S. E., Flynn, M. C., Langhans, W., Schwartz, G. J., et al. (2001). Pro-inflammatory and anti-inflammatory cytokine mRNA induction in the periphery and brain following intraperitoneal administration of bacterial lipopolysaccharide. Brain Res. Bull. 54, 443-453.

Ueno, M., Fujita, Y., Tanaka, T., Nakamura, Y., Kikuta, J., Ishii, M., et al. (2013). Layer V cortical neurons require microglial support for survival during postnatal development. Nat. Neurosci. 16, 543-551. doi: 10.1038/nn.3358

Valdearcos, M., Robblee, M. M., Benjamin, D. I., Nomura, D. K., Xu, A. W., and Koliwad, S. K. (2014). Microglia dictate the impact of saturated fat consumption on hypothalamic inflammation and neuronal function. Cell Rep. 9, 2124-2138. doi: 10.1016/j.celrep.2014.11.018

Vallee, M., Mayo, W., Dellu, F., Le Moal, M., Simon, H., and Maccari, S. (1997). Prenatal stress induces high anxiety and postnatal handling induces low anxiety in adult offspring: correlation with stress-induced corticosterone secretion. J. Neurosci. 17, 2626-2636.

van Praag, H., Kempermann, G., and Gage, F. H. (2000). Neural consequences of environmental enrichment. Nat. Rev. Neurosci. 1, 191-198. doi: 10.1038/ 35044558

Varese, F., Smeets, F., Drukker, M., Lieverse, R., Lataster, T., Viechtbauer, W., et al. (2012). Childhood adversities increase the risk of psychosis: a meta-analysis of patient-control, prospective- and cross-sectional cohort studies. Schizophr. Bull. 38, 661-671. doi: 10.1093/schbul/sbs050 
Voineagu, I., Wang, X., Johnston, P., Lowe, J. K., Tian, Y., Horvath, S., et al. (2011). Transcriptomic analysis of autistic brain reveals convergent molecular pathology. Nature 474, 380-384. doi: 10.1038/nature10110

Volk, H. E., Lurmann, F., Penfold, B., Hertz-Picciotto, I., and McConnell, R. (2013). Traffic-related air pollution, particulate matter, and autism. JAMA Psychiatry 70, 71-77. doi: 10.1001/jamapsychiatry.2013.266

Wake, H., Moorhouse, A. J., Jinno, S., Kohsaka, S., and Nabekura, J. (2009). Resting microglia directly monitor the functional state of synapses in vivo and determine the fate of ischemic terminals. J. Neurosci. 29, 3974-3980. doi: 10.1523/JNEUROSCI.4363-08.2009

Wakselman, S., Bechade, C., Roumier, A., Bernard, D., Triller, A., and Bessis, A. (2008). Developmental neuronal death in hippocampus requires the microglial CD11b integrin and DAP12 immunoreceptor. J. Neurosci. 28, 8138-8143. doi: 10.1523/JNEUROSCI.1006-08.2008

Wiesel, T. N., and Hubel, D. H. (1963). Single-cell responses in striate cortex of kittens deprived of vision in one eye. J. Neurophysiol. 26, 1003-1017.

Williamson, L. L., and Bilbo, S. D. (2014). Neonatal infection modulates behavioral flexibility and hippocampal activation on a Morris Water Maze task. Physiol. Behav. 129, 152-159. doi: 10.1016/j.physbeh.2014.02.033

Williamson, L. L., Chao, A., and Bilbo, S. D. (2012). Environmental enrichment alters glial antigen expression and neuroimmune function in the adult rat hippocampus. Brain Behav. Immun. 26, 500-510. doi: 10.1016/j.bbi.2012.01.003

Williamson, L. L., Sholar, P. W., Mistry, R. S., Smith, S. H., and Bilbo, S. D. (2011). Microglia and memory: modulation by early-life infection. J. Neurosci. 31, 15511-15521. doi: 10.1523/JNEUROSCI.3688-11.2011

Wu, L. J., and Zhuo, M. (2008). Resting microglial motility is independent of synaptic plasticity in mammalian brain. J. Neurophysiol. 99, 2026-2032. doi: 10.1152/jn.01210.2007

Wu, Y., Dissing-Olesen, L., MacVicar, B. A., and Stevens, B. (2015). Microglia: dynamic mediators of synapse development and plasticity. Trends Immunol. 36, 605-613. doi: 10.1016/j.it.2015.08.008

Xu, H., Gelyana, E., Rajsombath, M., Yang, T., Li, S., and Selkoe, D. (2016). Environmental enrichment potently prevents microglia-mediated neuroinflammation by human amyloid beta-protein oligomers. J. Neurosci. 36, 9041-9056. doi: 10.1523/JNEUROSCI.1023-16.2016
Yin, F., Banerjee, R., Thomas, B., Zhou, P., Qian, L., Jia, T., et al. (2010). Exaggerated inflammation, impaired host defense, and neuropathology in progranulin-deficient mice. J. Exp. Med. 207, 117-128. doi: 10.1084/jem. 20091568

Zabel, M. K., and Kirsch, W. M. (2013). From development to dysfunction: microglia and the complement cascade in CNS homeostasis. Ageing Res. Rev. 12, 749-756. doi: 10.1016/j.arr.2013.02.001

Zhan, Y., Paolicelli, R. C., Sforazzini, F., Weinhard, L., Bolasco, G., Pagani, F., et al. (2014). Deficient neuron-microglia signaling results in impaired functional brain connectivity and social behavior. Nat. Neurosci. 17, 400-406. doi: 10.1038/ nn.3641

Zhang, J., Malik, A., Choi, H. B., Ko, R. W., Dissing-Olesen, L., and MacVicar, B. A. (2014). Microglial CR3 activation triggers long-term synaptic depression in the hippocampus via NADPH oxidase. Neuron 82, 195-207. doi: 10.1016/j.neuron. 2014.01.043

Zhao, Q., Xie, X., Fan, Y., Zhang, J., Jiang, W., Wu, X., et al. (2015). Phenotypic dysregulation of microglial activation in young offspring rats with maternal sleep deprivation-induced cognitive impairment. Sci. Rep. 5:9513. doi: 10.1038/ srep09513

Zhu, F., Zheng, Y., Liu, Y., Zhang, X., and Zhao, J. (2014). Minocycline alleviates behavioral deficits and inhibits microglial activation in the offspring of pregnant mice after administration of polyriboinosinic-polyribocytidilic acid. Psychiatry Res. 219, 680-686. doi: 10.1016/j.psychres.2014. 06.046

Conflict of Interest Statement: The authors declare that the research was conducted in the absence of any commercial or financial relationships that could be construed as a potential conflict of interest.

Copyright (c) 2017 Paolicelli and Ferretti. This is an open-access article distributed under the terms of the Creative Commons Attribution License (CC BY). The use, distribution or reproduction in other forums is permitted, provided the original author(s) or licensor are credited and that the original publication in this journal is cited, in accordance with accepted academic practice. No use, distribution or reproduction is permitted which does not comply with these terms. 